\title{
Electrochemically Obtained Insulating and Conducting Polymers and Composites of Acrylonitrile
}

\section{B. Y. YILMAZ , U. AKBULUT \& L. TOPPARE*}

To cite this article: B. Y. YILMAZ , U. AKBULUT \& L. TOPPARE* (1998) Electrochemically Obtained Insulating and Conducting Polymers and Composites of Acrylonitrile, Journal of Macromolecular Science, Part A, 35:2, 261-291, DOI: 10.1080/10601329808001977

To link to this article: http://dx.doi.org/10.1080/10601329808001977

曲 Published online: 15 Aug 2006.

Submit your article to this journal $\pi$

山 Article views: 30

Q View related articles $\sqsubset$

Citing articles: 3 View citing articles 5 


\title{
ELECTROCHEMICALLY OBTAINED INSULATING AND CONDUCTING POLYMERS AND COMPOSITES OF ACRYLONITRILE
}

\author{
Berrin Yurttas Yilmaz \\ Kordsa A. S. 41001 \\ Izmit, Turkey \\ Ural Akbulut \\ Department of Chemistry \\ Middle East Technical University \\ 06531 Ankara, Turkey \\ Levent Toppare * \\ Department of Chemistry \\ Bilkent University \\ 06533 Ankara, Turkey
}

\begin{abstract}
Electrochemically obtained polyacrylonitrile and a commercial polyacrylonitrile were heat treated to improve their conductivities. The parameters chosen for heat treatment conditions were the temperature, treatment medium (vacuum or air) and, doping agent. The conductivity of all heat treated polymers was measured. The characterization of the heat treated polymers was made by IR analysis. The composite films of polyacrylonitrile with polypyyrole and polythiophene were electrochemically prepared at different compositions. The change in the conductivity of composites was analyzed as a function of the percent composition of the insulating component. IR, DSC, TGA and SEM analyses were used to characterize the polymer composites.
\end{abstract}




\section{INTRODUCTION}

Polyacrylonitrile (PAN) is one of the precursor materials used for the com mercial production of carbon fibers. The reason for this is that a low temperature heat treatment of textured fiber leads to the formation of the thermally stable, highly oriented molecular structure which is not catastrophically disrupted during the carbonization treatment $[1,2]$. It was also known that when subjected to special heat treatment PAN acquires semiconducting properties.

The heat treatment includes; first, an oxidative stabilization of precursor fibers to prevent melting or fusing together. Second, a carbonizing heat treatment to drive off the majority of non-carbon elements takes place. Third, an optional high temperature treatment, often called graphitizing is designed to improve the mechanical properties of the carbon fiber. The temperature for three steps for PAN heat treatment is $220^{\circ} \mathrm{C}, 1000-1500^{\circ} \mathrm{C}$ and above $3000^{\circ} \mathrm{C}$, respectively.

Acrylonitrile polymerizes through the carbon-carbon double bond, producing a linear macromolecule containing nitrile side groups. Since the nitrile groups are unsaturated, there exists the possibility of an additional polymerization reaction through them. This reaction may be induced by simply heating the polymer. The stabilization through nitrile polymerization results in a thermally stable cyclized structure. Stabilization is accompanied by the color change of fiber from white through shades of yellow late turning to reddish brown and finally black arising from the formation of chromophore in the cyclized nitrile structure.

Depending on the heat treatment parameters including furnace temperature, time of stabilization, furnace environment and the precursor fiber characteristics different types of chemical structures were proposed for the oxidized PAN [3]. Heat treatment of PAN evolves mainly ammonia, hydrogen cyanide, water, nitrogen, hydrogen, oxides of carbon, hydrocarbons and nitriles [2-7].

It was found that the presence of Lewis acids increases the formation rate of the thermally stable structure. The polymerization can be assumed to be ionic rather than free radical and the Lewis acid should play a role in the mechanism. The formation of a complex between the nitrile and the Lewis acid was expected [2].

Pyrolyzed PAN (PANP) is well known for its high electrical conductivity (up to $20 \mathrm{~S} / \mathrm{cm}$ ). Fibers of PAN may also be transformed to electrically conductive PANP giving highly conducting woven material [8]. The electrical resistivity of PAN fibers is as high as $\approx 10^{6} \Omega \mathrm{cm}$ whereas, that of carbon fibers is $10^{-2}-10^{-4}$ $\Omega \mathrm{cm}$, but never as low as well ordered graphite $\left(4 \times 10^{-5} \Omega \mathrm{cm}\right)$. The authors have found that the major decrease in resistivity occurs below $1000^{\circ} \mathrm{C}$, possibly with the greatest rate of decrease at $\approx 600^{\circ} \mathrm{C}$ [1]. 
Recent studies on cast films of PAN (mol wt 485,000 or 15,000) resulted in PANP forming at temperatures of $390-435^{\circ} \mathrm{C}$, which have conductivity as high as $5 \Omega^{-1} \mathrm{~cm}^{-1}$.

It is possible to introduce PANP with $n$ - and p-type conductance, depending on the conditions of preparation. Pyrolysis in vacuum, at temperatures of $340^{\circ} \mathrm{C}$ and $710^{\circ} \mathrm{C}$, leads to PANP with a n-type conductance. Probably due to an absorbed oxygen p-type, conductance of PANP can be achieved at temperatures $500^{\circ} \mathrm{C}$ and $700^{\circ} \mathrm{C}[8,9]$.

The other class of conductive synthetic materials are the polymers whose backbone are responsible for the generation or propagation of charge carriers. The introduction of acetylene black and later other conductive materials led to the production of rubbers having appreciable conductivity. The mechanical properties of early stage conducting polymers were poor but, later generations have mechanical properties approaching to insulating polymers. Sometimes, products which were intended to be insulating were found to have significant conductivity [10]. To date, only few polymers; polyaniline, polypyrrole, polyacetylene has been commercialized due to their environmental stability and level of conductance in plastic battery electrodes, static dissipation films, etc.

The most commonly faced problem in conducting polymers is the poor mechanical properties which create processing problems. Recent studies and this report are concentrated on obtaining conducting polymers and polymer blends. One of the applied techniques is to produce polymer blends of an insulating matrix and a conducting component. As a result, it was claimed that the mechanical property of the conducting component can be improved [11].

Electrochemical preparation of composites of PPy with an insulating polymer, polyamide, was also carried out by L. Toppare et al. [12]. They obtained a composite in which there exists $\mathrm{H}$-bonding between the two polymers and a possible grafting to a certain extent.

An investigation about PAN-PPy composite films has been carried out by Bhat et al. PAN was used as the polymeric matrix that was prepared by dissolving PAN in DMF and followed by addition of $\mathrm{FeCl}_{3}$ as the oxidizing agent. A few drops of this solution was poured on a glass plate and dried. This film was exposed to pyrrole vapor at room temperature. Formation of composite film of PAN-PPy was established by IR and thermal analysis. The films showed improved thermal stability and electrical conductivity. The resistivity of PAN was determined as 16 $\mathrm{M} \Omega \mathrm{cm}$ and increased gradually up to $20 \mathrm{~K} \Omega \mathrm{cm}$ with increasing incorporation of PPy (5.8 wt \% PPy). The strength of the composite film decreased as compared to pure PAN [9]. 
In this work we examined the electrical conductivity behavior of pyrolized PAN and the blends of PPy and PTh with PAN. PAN was electrochemically obtained by constant potential electrolysis. The details of electrochemical polymerization has been discussed in our earlier paper [13].

\section{EXPERIMENTAL}

\section{Heat Treatment of Polyacrylonitrile}

Electrochemically obtained and a commercial PAN (Aldrich Chem. Comp. Inc.) were used in pelletized form for all heat treatments. The pellets were prepared at 1000 psi for 7 minutes prior to heat treatment. Samples which will be treated under atmospheric conditions, were directly placed in the oven. Samples which were treated under vacuum were first connected to vacuum line for degassing purposes. The sealed samples were than placed in the oven. Treatments of PAN in the presence of dopant were carried out by using a pair of test tubes connected to each other. Direct contact of doping agent with PAN was avoided. Those which were carried out under vacuum were degassed and isolated before treatment.

The heat treatment of PAN was carried out at three different temperatures namely, 200,400 and $600^{\circ} \mathrm{C}$. The oven temperature was increased gradually and kept constant at the desired temperature for two hours. In the case of multi-step heat treatments, such as 200 and $400^{\circ} \mathrm{C}$, the sample was kept at $200^{\circ} \mathrm{C}$ for two hours and then the oven temperature was increased to $400^{\circ} \mathrm{C}$ gradually. The sample was allowed to stay at that temperature for another two hours. The effect of dopant at different temperatures and environmental conditions was also investigated. For that purpose, $\mathrm{AlCl}_{3}$ was used as a dopant. The details of the heat treatment procedure and the conditions were summarized in Table 1. The conductivity measurements and IR analysis of the heat treated samples were carried out.

\section{Preparation of PAN-PPy and PAN-PTh Polymer Blends.}

Different electrolysis conditions were applied during the polymer blend preparation. These conditions were summarized in Table 2 for PAN-PPy blends and in Table 3 for PAN-PTh blends.

PAN-PPy and PAN-PTh composites were prepared by the electrochemical polymerization of Py and Th on a PAN coated electrode separately. The constant potential electrolyses were carried at the oxidation potential of Py or Th. Dichlor omethane was used as the polymerization solvent, and tetrabutylammonium fluoroborate (TBAFB) as the electrolyte. The remaining components of the electrolysis 


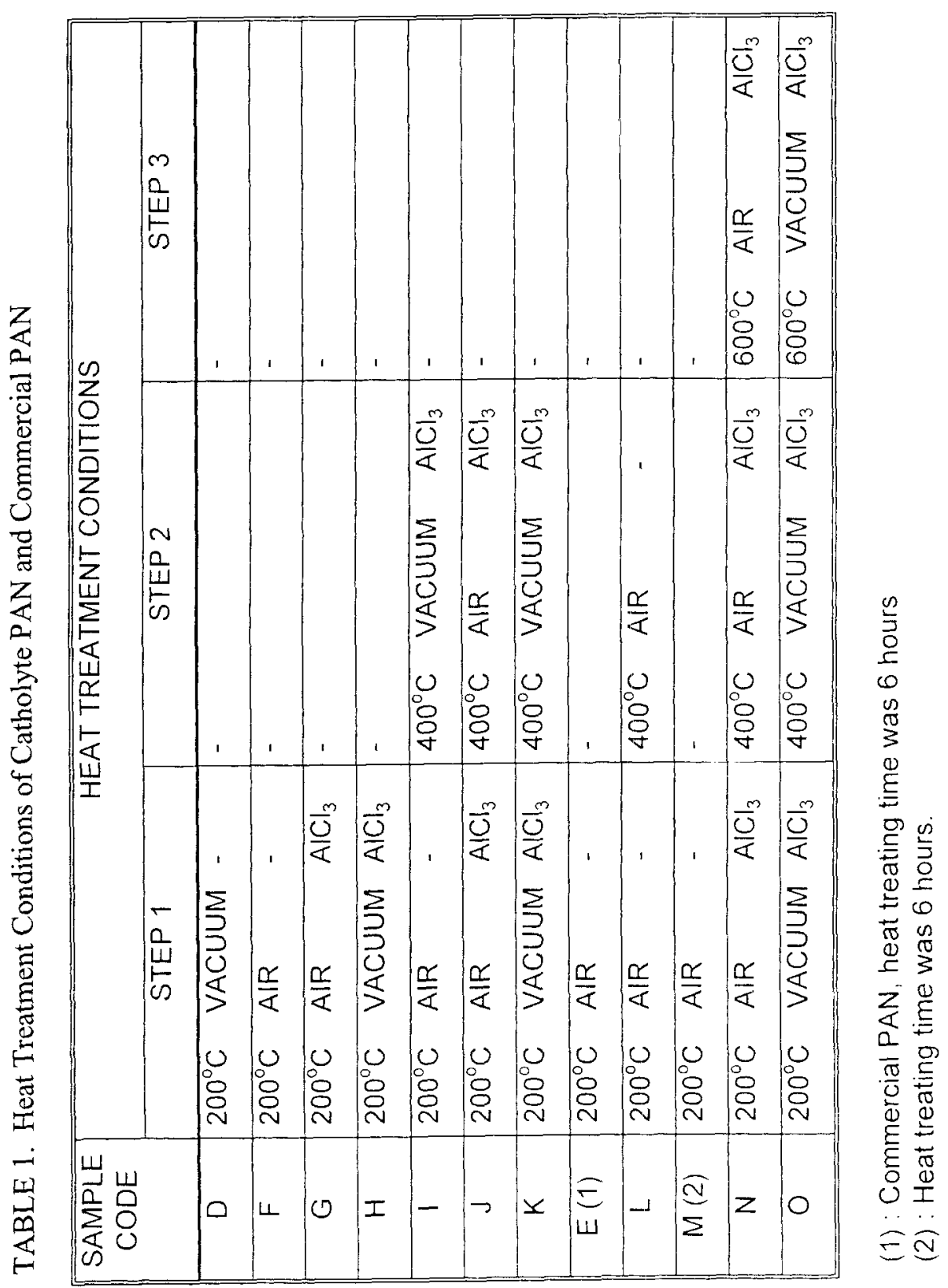




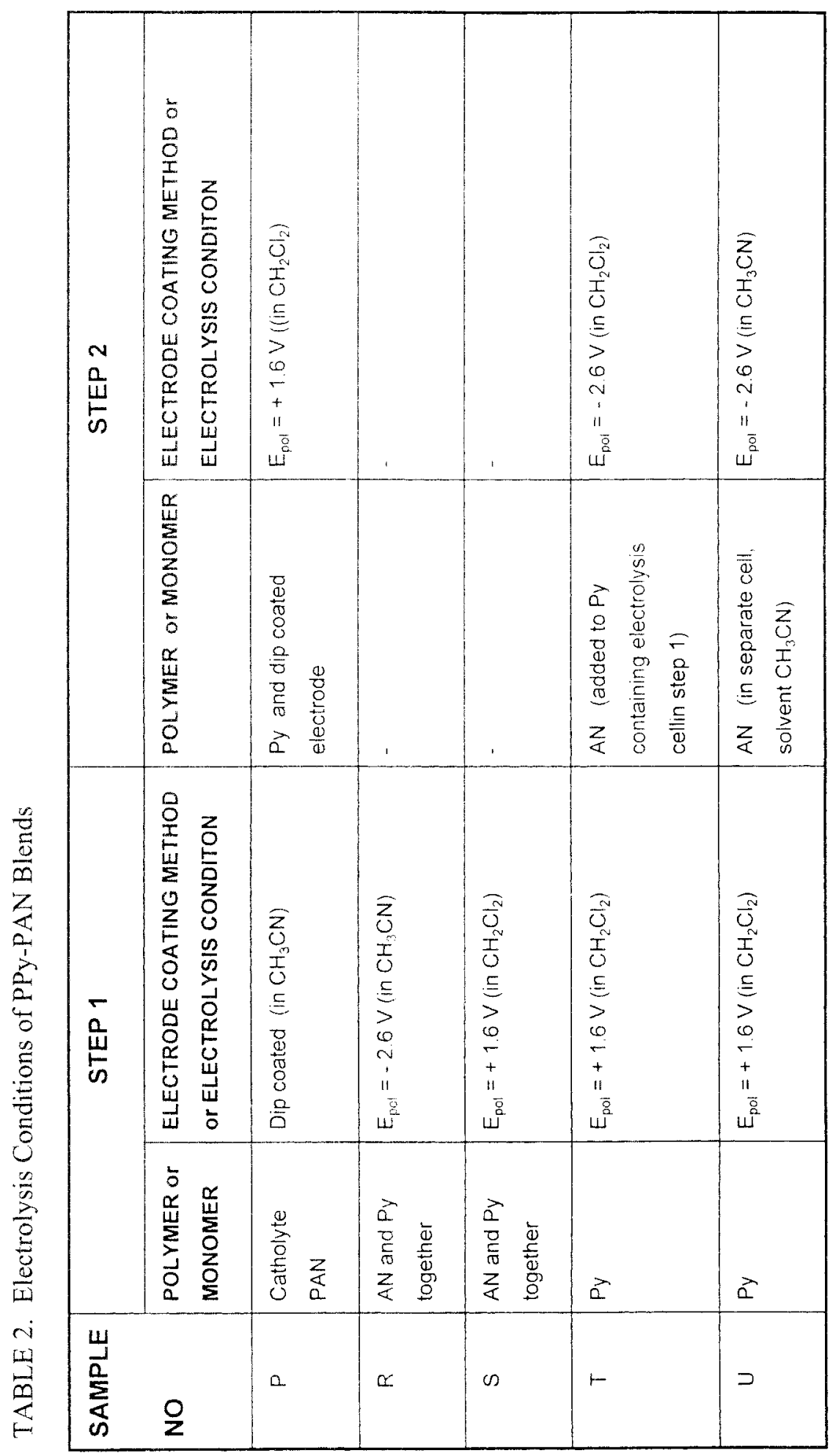




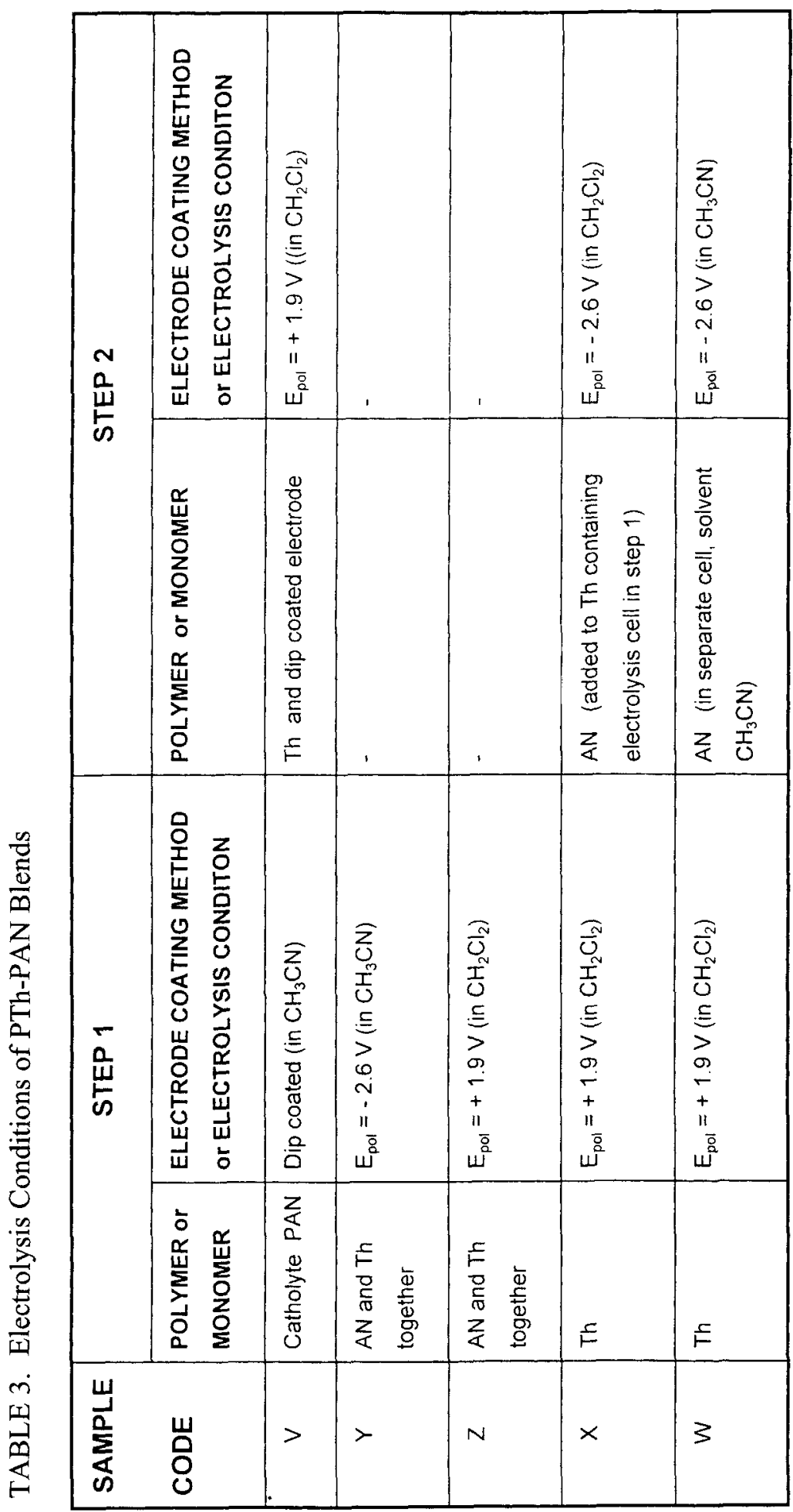


cell were Pt foil $\left(2 \mathrm{~cm}^{2}\right)$ working and counter electrodes and a Luggin capillary $\left(\mathrm{Ag}^{\circ} / \mathrm{Ag}^{+} 10^{-2} \mathrm{M}\right)$ reference electrode. The electrolysis cell was purged with $\mathrm{N}_{2}$ throughout the polymerization. In both cases, namely PAN - PPy and PAN - PTh blend syntheses, $10^{-3} \mathrm{M}$ monomer was introduced into the electrolysis cell. The polymerizations were carried out at room temperature. Electrochemically prepared yellow polyacrylonitrile was dissolved in acetonitrile, the working electrode (anode) was dip coated from this solution. The coated electrode was placed in the electrolysis cell. The potential was switched on and the electrolysis was allowed to proceed till obtaining the desired conducting the polymer percentage. After electrolyses, anode was removed from the cell and immersed into dichloromethane and acetonitrile for quick washing process (samples $\mathrm{P}$ and $\mathrm{V}$ ). The film on the electrode surface was peeled off for further gravimetric, conductivity, thermal and FTIR, SEM analyses. The electrochemical behavior of dip coated PAN was analyzed by running the electrolysis in the absence of Py or Th in the electrolysis cell. No weight change was observed on the polymer electrode.

In the second group experiments, the possibility of obtaining polymer blends, when both acrylonitrile and pyrrole (or thiophene) were present in the electrolysis, medium was studied. First, the acrylonitrile component was considered. Therefore, acetonitrile was used as the solvent and the reduction peak potential of acrylonitrile was applied (samples $\mathrm{R}$ and $\mathrm{V}$ ). Second, the oxidation peak potential of pyrrole (or thiophene) was applied where the working electrode was anode and the solvent was dichloromethane (samples $\mathrm{S}$ and $\mathrm{Z}$ ). Those two analyses were done in separate systems.

In the third group experiments, the heterocyclic monomers were polymerized at their oxidation potentials in dichloromethane until conducting polymer electrode films were formed. As soon as the film reached a certain thickness (20 $\mu \mathrm{m}$ ), the electrochemically coated electrode was removed and immersed in another electrolysis cell. This new cell contains acrylonitrile monomer, and the solvent was acetonitrile. The polymerization potential was the $\mathrm{E}_{p, c}$ of acrylonitrile (samples $\mathrm{T}$ and $\mathrm{X}$ ). Another version of that group experiment was the addition of acrylonitrile monomer to the polypyrrole or polythiophene system after conducting electrode film formation. After addition of acrylonitrile to the cell the potential was reversed to the $\mathrm{E}_{p, c}$ of the acrylonitrile (samples $\mathrm{U}$ and $\mathrm{W}$ ).

Polymerization of pure PPy and PTh was carried out in the same three electrode system under controlled potential conditions. The cell was equipped with Pt foils $\left(2 \mathrm{~cm}^{2}\right)$ as the working and the counter electrodes and a capillary $\mathrm{Ag}^{\circ} / \mathrm{Ag}+$ as the reference electrode. Dichloromethane was used as the solvent and TBAFB 
was used as the electrolyte. Monomer either Py or Th $\left(10^{-3} \mathrm{M}\right)$ was charged into the electrolysis cell. The polymerizations were carried out at room temperature and at the oxidation potential of either Py or Th. The electrolysis was allowed to proceed until obtaining sufficiently thick films (c.a. $40 \mu \mathrm{m}$ ). The electrodes were removed from the cell, polymer films were peeled off from the electrode surface and washed with dichloromethane. The percentage of polyacrylonitrile, polypyrrole and polythiophene in blends were determined gravimetrically.

The details of cyclic voltammetry and constant potential electrolysis of PAN were discussed in earlier reports [13]. The electrochemical behavior of PPy and PTh was determined by using a acetonitrile-TBAFB system where the reference electrode was $\mathrm{Ag}^{\circ} / \mathrm{Ag}^{+}$. An oxidation peak for PPy film was observed at $+0.7 \mathrm{~V}$ on the anodic sweep and a corresponding reduction peak was observed at around +0.20 $\mathrm{V}$ in the cathodic sweep. The detailed analysis of electrochemical behavior of PPy film under different conditions was reported [14]. PTh film has an oxidation peak at $+1.25 \mathrm{~V}$ on the anodic sweep and the corresponding reduction peak at $+1.00 \mathrm{~V}$ on the cathodic sweep [15].

The conductivities of heat treated PAN and polymer blends were measured by four probe technique. The polymers were characterized by IR (Perkin Elmer 177), thermal DSC (Du Pont V2.A 9900) and TGA (Du Pont V2.0B 9900) and SEM (Jeol JSM 840A) analyses.

\section{RESULTS AND DISCUSSION}

\section{Heat Treatment of Polyacrylonitriles and Determination of Their Conductivities and Characterization}

Polyacrylonitrile is a precursor polymer of carbon fibers which shows conducting properties up to a certain degree. The inter and intra molecular cyclization of polyacrylonitriles produce a conducting structure. In this study, we have a certain degree of cyclization that was revealed by yellow to brown coloration of polymers [13]. The conductivity behavior of electrochemically obtained polymers was investigated. The commercial uncyclized white PAN was also used as a reference sample.

Our aim was to obtain polyacrylonitrile films for further analysis. Therefore, colored catholyte polymer was heated up to $300^{\circ} \mathrm{C}$ under different pressures, but unfortunately no melting was observed. On the other hand, the color of the polymer got darker (yellow to brown). The same procedure was applied to commercial white polyacrylonitrile. Same as the electrochemical product, no melting but color change was observed. The degree of coloring in the electrochemical product 
was higher. In other words, the rate of cyclization through nitrile groups was higher. The thermal analysis of these polyacrylonitriles also supported this behavior.

Heat treatments of catholyte PAN and commercial white PAN were performed at different conditions. The conductivities of these polymers were measured. Electrochemical polymerization results in the polymerization through the carbon carbon double bond and additional polymerization through unsaturated nitrile groups to some extent. The further (through nitrile group) polymerization was enhanced by simply heating the polymer. As a consequence of that heating, thermally stable cyclized structures which are often referred to as ladder polymers were produced. In the literature there are various proposals for the mechanism of cyclization [1-3].

During the heat stabilization of polymers different gaseous products like ammonia and hydrogen cyanide were evolved [2-7]. The [orous appearance of heat treated pellets was attributed to the above mentioned gas evolution. It was observed that as the heat treatment temperature was increased the porosity was also increased.

In conclusion, it was clearly observed that, the presence of Lewis acid increased the conductivity. Another observation was the positive effect of temperature. At high temperatures, namely $400^{\circ} \mathrm{C}$, a plateau of $10^{-5} \mathrm{~S} . \mathrm{cm}^{-1}$ conductivity was observed.

In addition to the above analyses, several more experiments were also performed regarding conductivity. For instance, for the following conditions either before or after heat treatment, the polymer lost its ability to form pellets. Therefore, conductivity measurements were not carried out. Those conditions were: heat treatment at $200^{\circ} \mathrm{C}$ open to atmosphere for two hours followed by $400^{\circ} \mathrm{C}$ open to atmosphere for two hours (sample L); heat treatment at $200^{\circ} \mathrm{C}$ open to atmosphere for six hours (sample $\mathrm{M}$ ); heat treatment open to atmosphere and in the presence of $\mathrm{AlCl}_{3}$ at $200^{\circ} \mathrm{C}$ for two hours, followed by $400^{\circ} \mathrm{C}$ for two hours, finally $600^{\circ} \mathrm{C}$ for yet another two hours (sample N). When the heat treatment of pelletized catholyte polymer was carried out in a vacuum sealed tube and in the presence of $\mathrm{AlCl}_{3}$ at $200^{\circ} \mathrm{C}$ for two hours, followed by $400^{\circ} \mathrm{C}$ for two hours and finally $600^{\circ} \mathrm{C}$ for two hours, the sealed tube breakage was observed (sample $O$ ). Repeated analysis of those conditions resulted in the same tube break. This can be attributed to the increased cyclization rate due to high dopant concentration which causes the evolution of more gaseous products.

As mentioned previously [2], cathodic PAN film, though brittle, has a certain conductivity without any heat treatment. Heat treatment at $200^{\circ} \mathrm{C}$ increased the brittleness of the film. As a result, we could not perform the conductivity measurements. In addition, the other heat treatments were not applied for this sample. 


\section{IR Analyses of Heat Treated Polyacrylonitriles}

The change of IR spectrum of heat treated polyacrylonitriles was given in Figure 1. One of the major variations observed was the decrease of intensity and the splitting of nitrile band $\left(-\mathrm{C}(\mathrm{N})\right.$ at $2240 \mathrm{~cm}^{-1}$. This band totally disappears under high temperature heat treatment. The second major variation was the gradual decrease of methylene $\left(\mathrm{CH}_{2}\right)$ band vibration at $2940 \mathrm{~cm}^{-1}$ and deformation at 1450 $\mathrm{cm}^{-1}$. Same as the nitrile band, this peak totally disappears upon further cyclization. Upon heat stabilization a broadening in $1600-1000 \mathrm{~cm}^{-1}$ region was observed. As nitrile absorption at $2240 \mathrm{~cm}^{-1}$ decreases, conjugated $-\mathrm{C}=\mathrm{N}$ absorption increases at 1670 and $1590 \mathrm{~cm}^{-1}$. As coloration develops, increasing absorption was observed in the $1600-1500 \mathrm{~cm}^{-1}$ carbonyl stretching region. The incorporation of oxygen during heat treatment was assigned in the literature $[3,6]$.

\section{Thermal Analysis of Polyacrylonitrile}

Thermal analysis of the catholyte yellow polymer and the commercial white polymer was carried out. DSC analysis indicated that both have no melting within the testing range. In other words, a maximum heat flow reflecting the decomposition of catholyte was observed at around $270{ }^{\circ} \mathrm{C}$, for the white polymer it was around $290^{\circ} \mathrm{C}$. A sharp decomposition peak for the white polymer and a broad one for the electrolytic one were observed. The difference was attributed to the structural difference (cyclization) (Figure 2).

In the case of TGA analysis, the weight loss (up to $600^{\circ} \mathrm{C}$ ) was higher for the catholyte polymer compared to the white polymer. The total loss was approximately $51 \%$ for the former and $30.5 \%$ for the latter. This can be correlated to the heat treatment behavior and the molecular structure of polyacrylonitrile. The color change was apparently higher in the electrolytic polymer. This color change was the indication of nitrile cyclization. Above $600^{\circ} \mathrm{C}$, the opposite behavior in weight loss was observed. That is, the weight losses were $46 \%$ for the electrolytic polymer and $62.7 \%$ for the commercial polymer (Figures 3, 4).

\section{Conducting Polymer Blends}

PAN-PPy and PAN-PTh composites were prepared by electrochemical polymerization of pyrrole (or thiophene) on PAN coated electrodes. In order to overcome the resistance caused by the insulating film, higher potentials were applied. PAN-PPy composites were prepared at $+1.5 \mathrm{~V}$, whereas PAN -PTh composites were at $+1.9 \mathrm{~V}$. PAN film was dip coated from acetonitrile solution. The amounts of insulating and conducting polymer coatings were determined grav- 

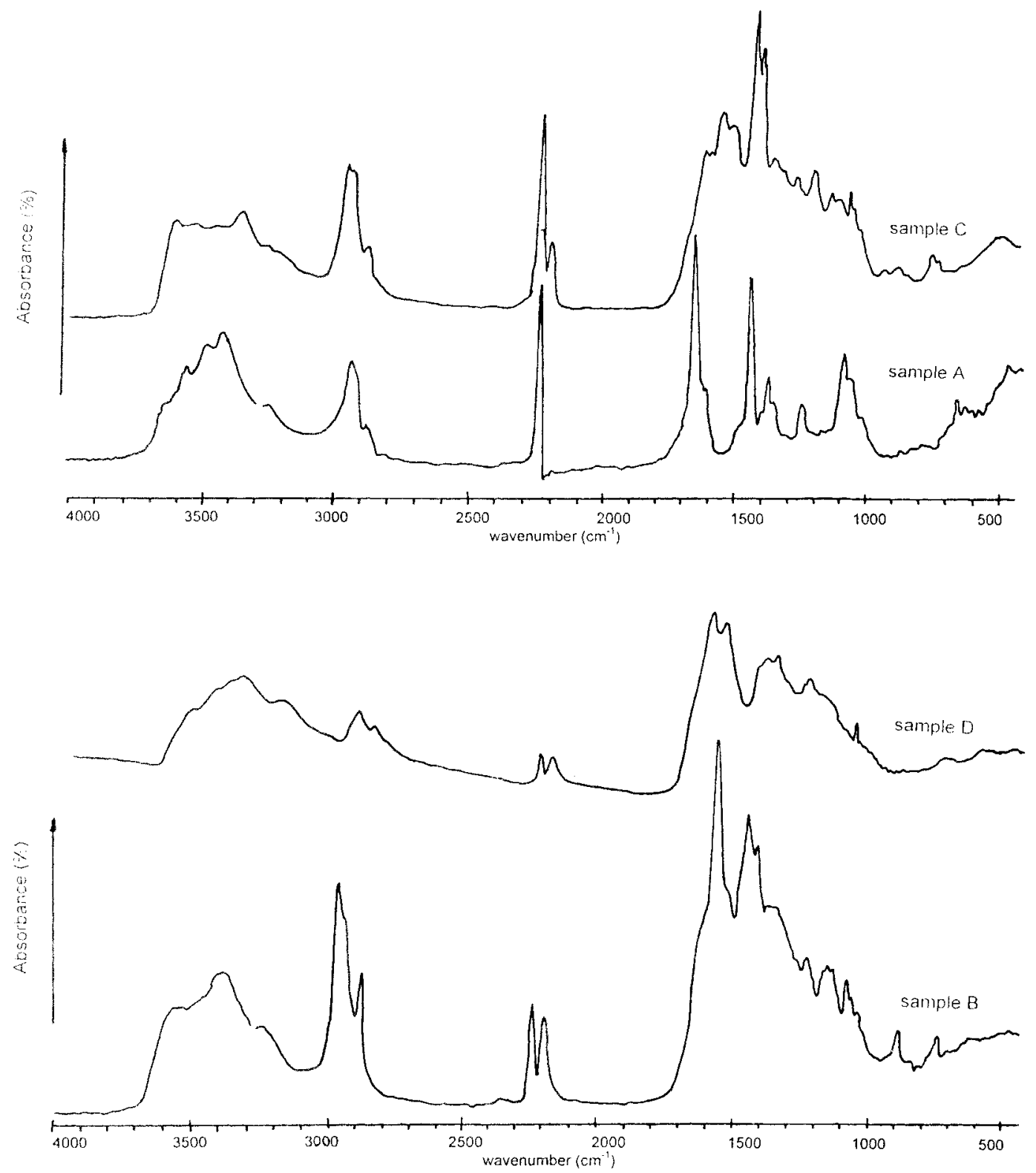

Figure 1. IR analysis of heat treated Polyacrylonitriles 

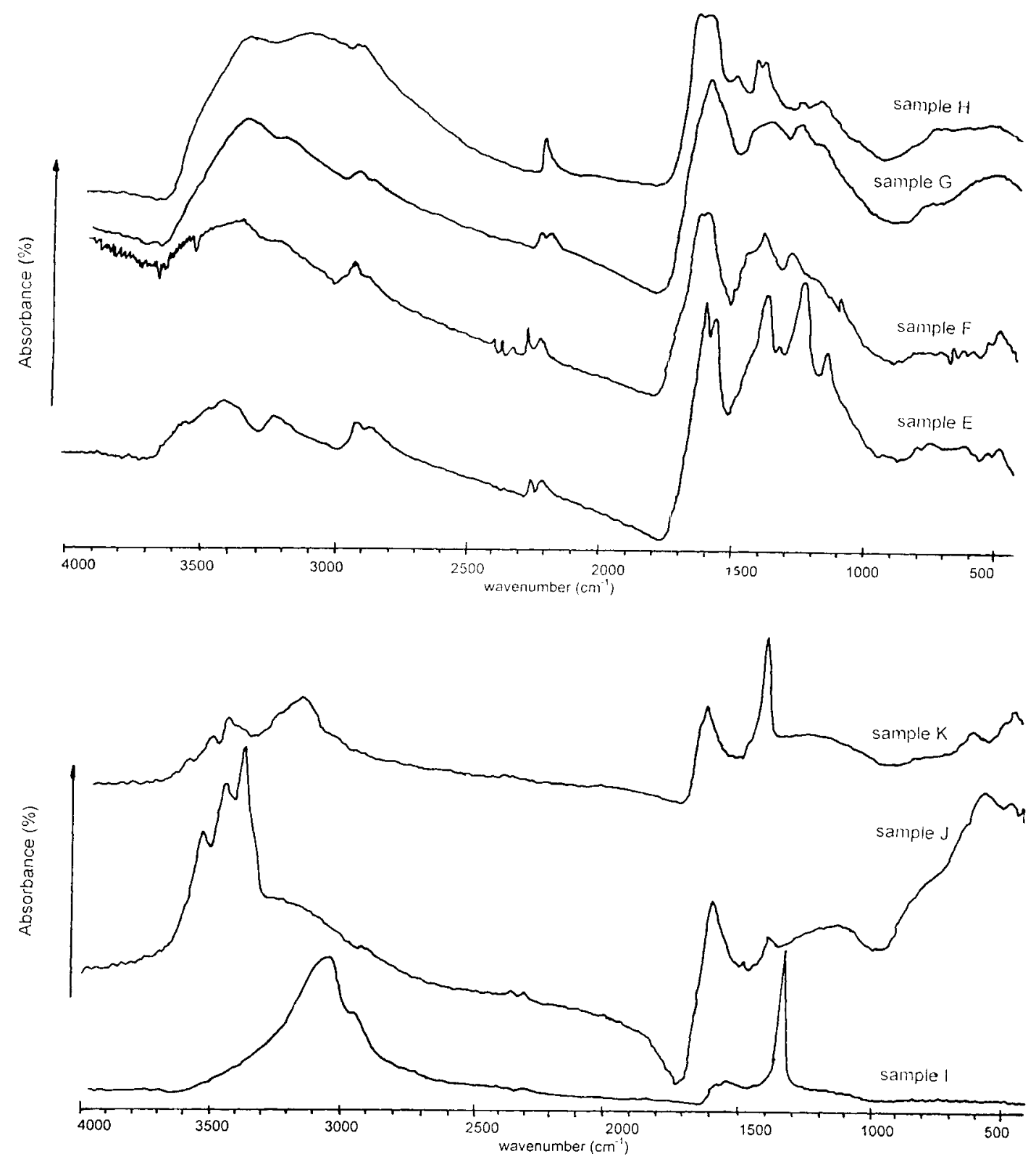

Figure 1. Continued 


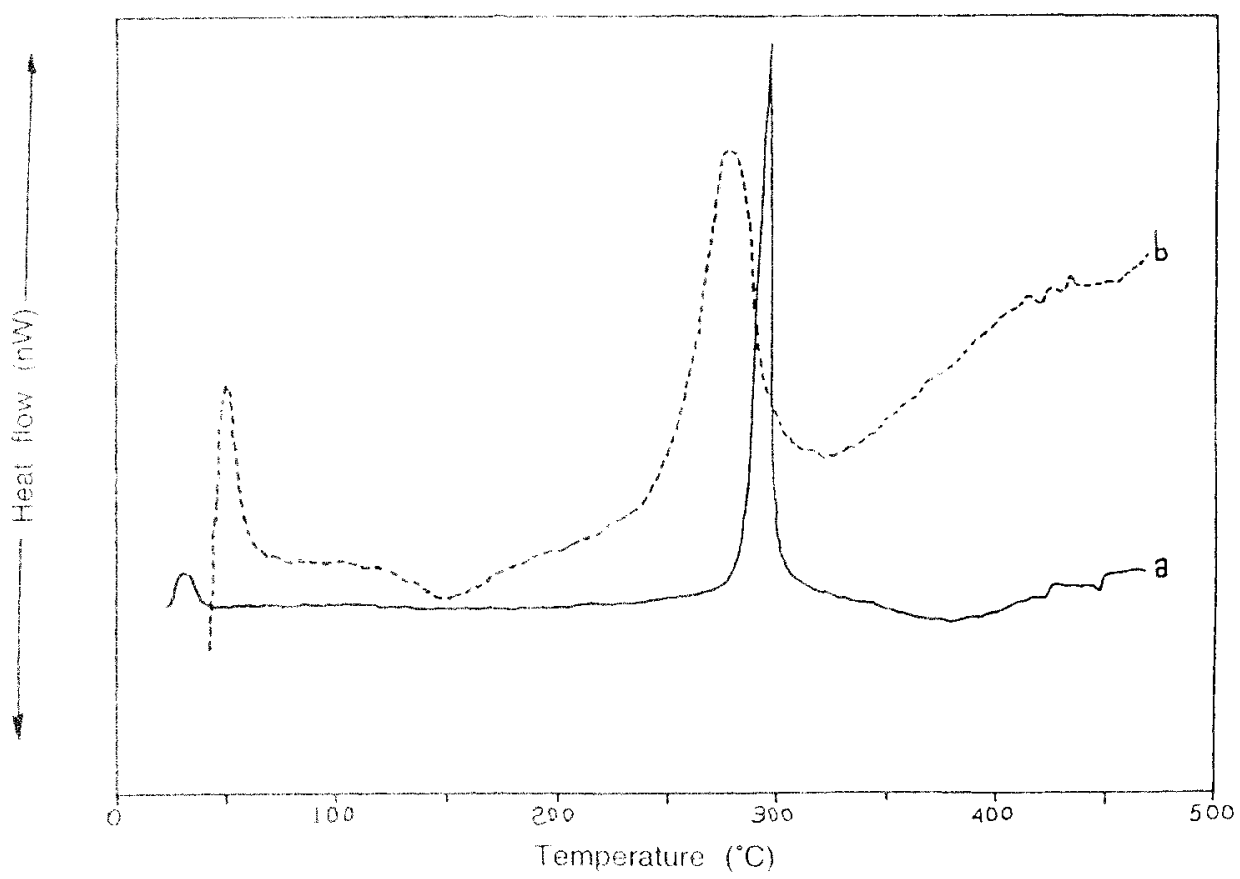

Figure 2. DSC thermogram of (a) commercial PAN, (b) cathodic PAN

imetrically. The amounts of PPy or PTh depositions were controlled by stopping the electrolysis at different time intervals.

The same type of experiments were planned for commercial white PAN, but we were unsuccesful to dissolve that polymer in acetonitrile, dichloroethane, DMF, chloroform, THF, acetone. However, the white polymer was soluble in dimethylsulfoxide (DMSO). Dip coating of the Pt electrodes was tried but it was difficult to evaporate DMSO under atmospheric conditions. Evaporation was done under vacuum conditions, but unfortunately a uniform film could not be prepared, instead, a highly wrinkled irregular film was produced. Since such types of films were not suitable for the polymerization of pyrrole (or thiophene) we could not attempt to synthesize blends with the commercial polymer.

After dip coating the working $(\mathrm{Pt})$ electrodes, syntheses of PPy were carried out at $+1.50 \mathrm{~V}$. Polyacrylonitrile coated on the Pt anode had a yellow color. When the electrolysis started, the monomer diffuses through the film towards electrode surface and forms a polymeric film between polyacrylonitrile and the electrode surface. The color of PPy blend was black and it was rather difficult to peel off the electrode surface. 
$(0 . \%) 146 ! ə M \cdot N ! \cdot 20$

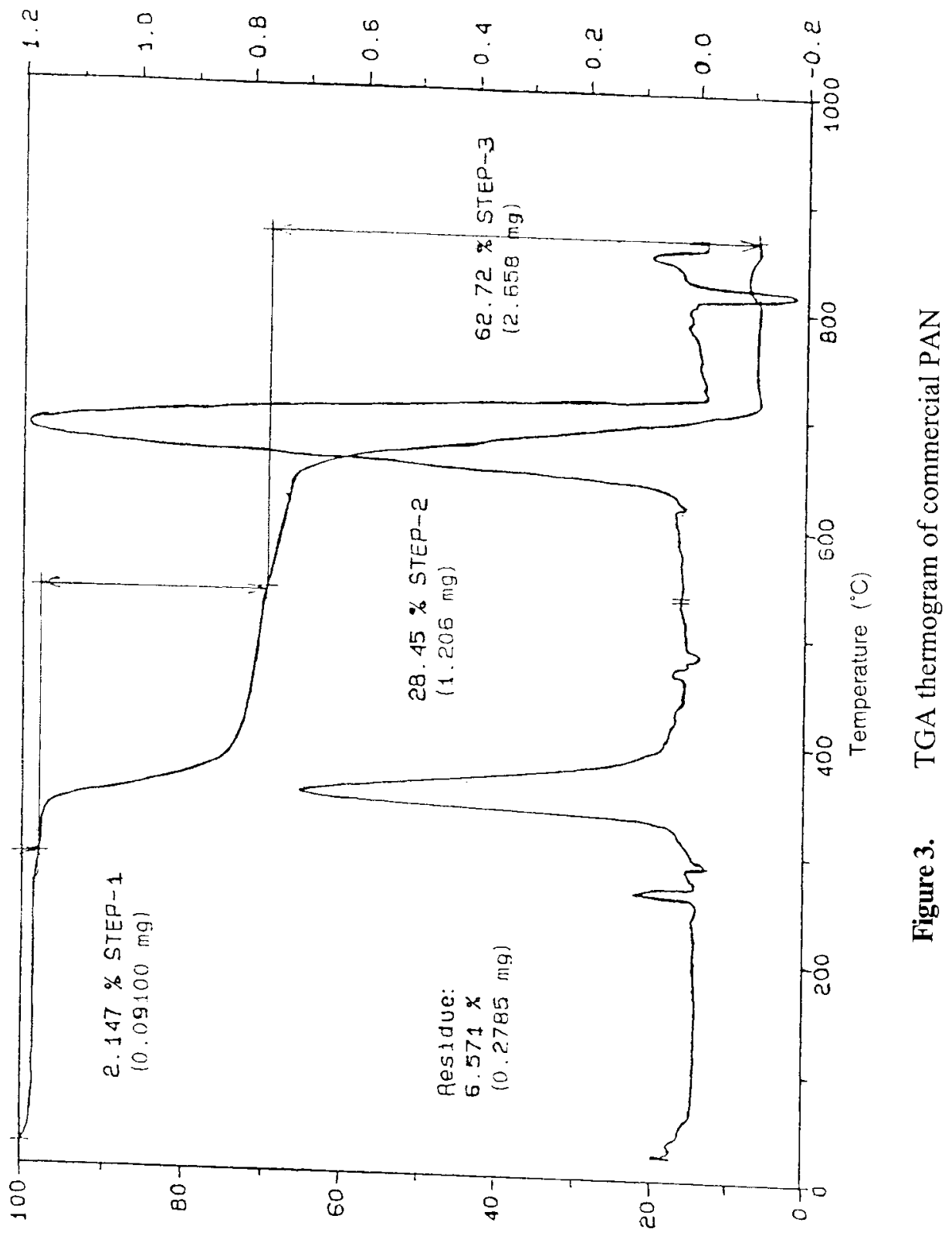

(\%) 
$(0 . \%)$ i46iam nuag

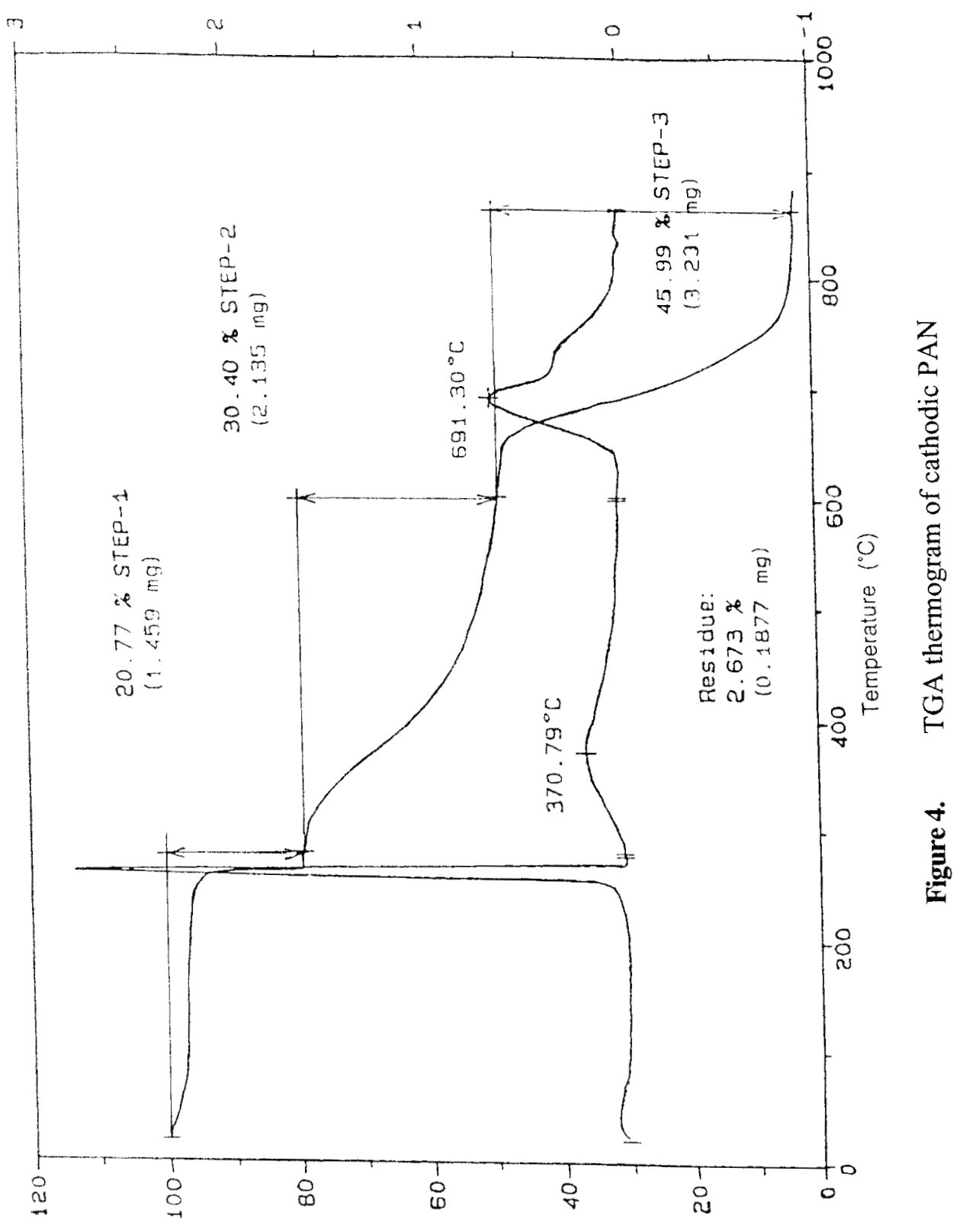

(\%) $14610 \mathrm{M}$ 
TABLE 4. The Conductivities of Pyrrole and Acrylonitrile Polymer Composites

\begin{tabular}{|c|c|c|}
\hline PPy & PAN & CONDUCTIVITY \\
\hline $\mathrm{Wt} \%$ & Wt $\%$ & $(\mathrm{~S} / \mathrm{cm})$ \\
\hline 0.00 & 100 & $2 \times 10^{-7}$ \\
\hline 20.97 & 79.03 & $4 \times 10^{-4}$ \\
\hline 37.14 & 62.86 & $3 \times 10^{-3}$ \\
\hline 60.00 & 40.00 & $3 \times 10^{-2}$ \\
\hline 67.51 & 32.47 & $4 \times 10^{-2}$ \\
\hline 70.00 & 30.00 & $5 \times 10^{-2}$ \\
\hline 84.19 & 15.81 & $6 \times 10^{-2}$ \\
\hline 100 & 0.00 & $7 \times 10^{-2}$ \\
\hline
\end{tabular}

As explained previously, blends of PAN with PPy at different percentages for each component (Table 4) were prepared. In the blends, PPy content ranged from $21 \%$ to $84 \%$. Pure PPy and PAN were used as the reference points. The

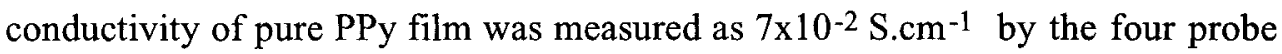
method. As the PPy incorporated into the matrix increased, the conductivity of the blend also increased (PAN conductivity $10^{-7} \mathrm{~S} / \mathrm{cm}$ ). For instance, incorporation of $21 \%$ PPy increased the conductivity to the order of $10^{-4} \mathrm{~S} . \mathrm{cm}^{-1}$, involvement of $37 \%$ PPy increased the conductivity to $10^{-3} \mathrm{~S} . \mathrm{cm}^{-1}$. Up to $70 \% \mathrm{PPy}$ contribution, the conductivity increased but then almost a plateau was observed. At that point, i.e., $70 \%$ PPy, a threshold conductivity was established. Thereon, the conductivity stayed about $10^{-2}$ S.cm ${ }^{-1}$.

The synthesis of thiophene on a precoated electrode was done at $+1.9 \mathrm{~V}$ vs $\mathrm{Ag}^{+} / \mathrm{Ag}^{\circ}$. As in the pyrrole case, polymerization of thiophene takes place between polyacrylonitrile film and the electrode surface. The PTh blend had a greenish black color, less sticky, and can easily be removed from the electrode surface as a freestanding film. 
TABLE 5. The Conductivities of Thiophene and Acrylonitrile Polymer Composites

\begin{tabular}{|c|c|c|}
\hline $\begin{array}{l}\text { PTh } \\
\text { Wt } \%\end{array}$ & $\begin{array}{l}\text { PAN } \\
\text { Wt } \%\end{array}$ & $\begin{array}{c}\text { CONDUCTIVITY } \\
(\mathrm{S} / \mathrm{cm})\end{array}$ \\
\hline 0.00 & 100 & $2 \times 10^{-7}$ \\
\hline 16.22 & 83.78 & $3 \times 10^{-4}$ \\
\hline 48.46 & 51.53 & $4 \times 10^{-3}$ \\
\hline 58.30 & 41.50 & $2 \times 10^{-2}$ \\
\hline 68.30 & 31.70 & $3 \times 10^{-2}$ \\
\hline 81.60 & 18.40 & $5 \times 10^{-2}$ \\
\hline 100 & 0.00 & $8 \times 10^{-2}$ \\
\hline
\end{tabular}

The blends were prepared by varying PTh and PAN contents. As a consequence of incorporation of PTh component in the blend, the conductivity increased (Table 5). The conductivity of pure PTh electrode film was in the order of $10^{-2}$ S.cm ${ }^{-1}$. Incorporation of $16 \%$ and $48.5 \%$ PTh increased the conductivity of the blends to $10^{-4}$ and $10^{-3} \mathrm{~S} . \mathrm{cm}^{-1}$, respectively. For higher percentages of PTh the conductivities in the order of $10^{-2} \mathrm{~S} . \mathrm{cm}^{-1}$ were observed. As with the PPy blends, the presence of almost $60 \%$ conducting component did not change the conductivity sharply. That is, it is possible to achieve a conductivity close to that of pure conducting polymer by incorporating $40 \%$ insulating polymer in the blends.

Preparations of conducting copolymers of acrylonitrile and pyrrole, acrylonitrile and thiophene were also investigated (Tables 2,3). They do not have the same type of electrochemical behavior, i.e. acrylonitrile can be cathodically polymerized, whereas the other two undergo oxidative polymerization. The redox potential of one monomer was chosen for the initiation of polymerization and involvement of the other in an indirect manner was assumed. For that purpose, Py and $\mathrm{AN}$ were introduced into the electrolysis cell containing acetonitrile as the 
solvent and $\mathrm{AN}$ reduction potential (-2.6 $\mathrm{V} \mathrm{vs} \mathrm{Ag}^{+} / \mathrm{Ag}^{\circ}$ ) was applied (sample $\mathrm{R}$ ). The same procedure was applied to Th and AN (sample Y). The surface of the cathode (working electrode) was not coated. Besides, a negligibly small amount of polyacrylonitrile was observed in the cathode compartment when the cell content was transferred into methanol. It was interesting that when acrylonitrile was homopolymerized in the same system in the absence of second component (Py or Th) considerably high polymer yields $(\approx 40 \%)$ were obtained.

The conducting copolymer synthesis was also investigated in the reverse manner. Again, Py-AN or Th-AN were introduced into the same electrolysis cell where the solvent was dichloromethane (sample $S$ and $Z$ ). The applied polymerization potential was $+1.50 \mathrm{~V}$ vs $\mathrm{Ag}^{+} / \mathrm{Ag}^{\circ}$ for Py-AN case and $+1.90 \mathrm{~V}$ for ThAN copolymerization. The purpose was to enhance the selective initiation of polymerization of the conducting component and indirect initiation of the polymerization for the insulating component. Anodic films were obtained but as the homopolymers of pyrrole and thiophene. The incorporation of acrylonitrile was not accomplished.

Another effort was to synthesize graft copolymers of Py and AN, Th and AN. It was proposed that the possibility of having graft copolymers can be verified first by obtaining a conducting polymer film and later by electropolymerizing the insulating component on the previously obtained film. Therefore, two different paths were followed after achieving the conducting film coating. Py and Th were polymerized on the surface of anode in DM at their own oxidation potentials. In the first path, the coated electrodes were placed in different cells separately. These cells contain AN monomer in acetonitrile. As soon as the electrodes were placed into the second cell the potential $\left(-2.6 \mathrm{~V}\right.$ vs $\left.\mathrm{Ag}^{+} / \mathrm{Ag}^{\circ}\right)$ was switched on. After one hour of electrolysis, we could not obtain any grafted polyacrylonitrile (samples $\mathrm{W}$ and $\mathrm{U}$ ). In the second path after conducting PPy and PTh, electrode films were synthesized in separate cells, AN monomer was introduced into the cell and $-2.6 \mathrm{~V} \mathrm{vs} \mathrm{Ag}^{+} / \mathrm{Ag}^{\circ}$ was applied (samples $T$ and $X$ ). Still, we could not observe any grafting of polyacrylonitrile on the prepolymerized PPy and PTh.

It necessary to emphasize that, in our earlier electrochemical polymerization studies, we frequently needed to increase the polymerization potential due to formation of the insulating polymer film. Sometimes we applied ultrasonic vibration to overcome the resistance created by the film $[14,16]$. Now in this work, it was clearly observed that although the films formed on the surface of the electrodes, their conductivities were sufficient to apply a desired polymerization potential. At least this was solid evidence of the presence of conductive films which themselves behave as electrodes. 

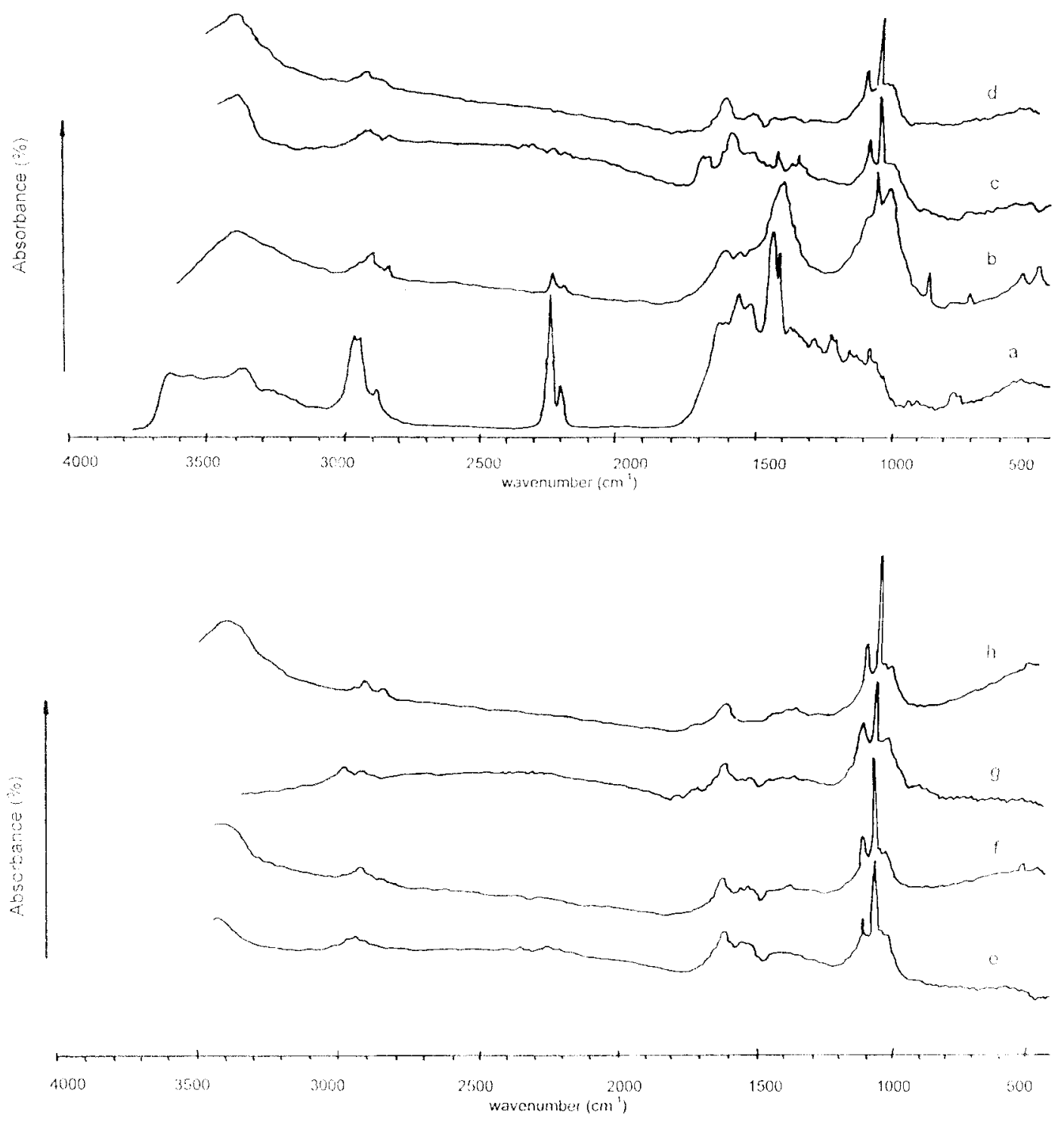

Figure 5. IR Spectra of PPy-PAN films (a) $100 \%$ PAN, (b) $79.03 \%$ PAN- 20.97\% PPy (c) 62.86\% PAN-37.14\% PPy, (d) $40 \%$ PAN-60\% PPy, (e) $32.47 \%$ PAN-67.51\% PPy, (f) $30 \%$ PAN-70\% PPy, (g) $15.81 \%$ PAN-84.19\% PPy, (h) $100 \%$ PPy 


\section{IR Analysis of PPy- PAN and PTh-PAN Films}

IR analyses of PPy-PAN and PTh-PAN blends were carried out as $\mathrm{KBr}$ pellets prepared at room temperature. Pure cathodic PAN IR absorption peaks are $3000,2240,1700-1400 \mathrm{~cm}^{-1}$. The incorporation of PPy or PTh affects the IR spectrum (Figure 5). For example, as $20 \%$ PPy was incorporated into the matrix, the absorption peaks of PAN at 3000 and $2240 \mathrm{~cm}^{-1}$ decreased considerably. The peaks in $1700-1400 \mathrm{~cm}^{-1}$ region were broadened. $1600-1000 \mathrm{~cm}^{-1}$ region stands for pyrrole ring and $1080 \mathrm{~cm}^{-1}$ for the tetraflouroborate anion. After reaching $60 \%$ PPy in the PPy-PAN film, the spectrum did not change considerably. The main absorptions, i.e. $\mathrm{C}=\mathrm{C}$ and $\mathrm{C}-\mathrm{H}$ vibrations for pure PPy was observed in the 1700 $1500 \mathrm{~cm}^{-1}$ and $1200-1000 \mathrm{~cm}^{-1}$ range.

IR spectra of PTh-PAN films are given in Figure 6. Since PTh films were rather more pulverizable compared to $\mathrm{PPy}$ film for $\mathrm{KBr}$ pellet preparation, better resolutions were obtained. Same as with the PPy-PAN films, incorporation of small amount PTh $(16 \%)$ caused a sharp decrease in 3000 and $2240 \mathrm{~cm}^{-1}$ peaks of PAN. After approximatelly $60 \%$ and at higher percentages of PTh in the film, no appreciable absorption change was observed.

\section{DSC Analysis of PPy-PAN and PTh-PAN Films}

The DSC and TGA analyses of PPy, PPy-PAN film and PTh-PAN film were performed.

In DSC analyses, pure PAN has an endothermic peak at $270^{\circ} \mathrm{C}$ (Figure $7 \mathrm{a}$ ). Under the same conditions, PPy decomposes above $300^{\circ} \mathrm{C}$ (Figure $7 \mathrm{~b}$ ). In DSC thermograms of PPy-PAN film, there exists two endothermic shoulders between $250^{\circ} \mathrm{C}$ and $350^{\circ} \mathrm{C}$. The film has an another endothermic peak at $400^{\circ} \mathrm{C}$ (Figure $7 \mathrm{c}$ ). Considering all the thermograms, the electrochemically prepared films were not simply the physical mixtures of the homopolymers.

For thiophene, same investigations were carried out. PTh has a quite different DSC thermogram compared to PPy. PTh has thermal behaviors between $270^{\circ} \mathrm{C}$ and $380^{\circ} \mathrm{C}$ (Figure $8 \mathrm{~b}$ ). PAN has a decomposition peak at $270^{\circ} \mathrm{C}$. In the PTh -PAN film an exothermic wide peak was observed between $90^{\circ} \mathrm{C}$ and $150^{\circ} \mathrm{C}$ (Figure 8c). Such behavior was not observed for both PPy and PAN homopolymers. The decomposition above $300^{\circ} \mathrm{C}$ continued up to $400^{\circ} \mathrm{C}$.

It is interesting that when the conducting component incorporates the film, that component dominates and shields the PAN behavior, and this was observed for both DSC and IR analyses. 

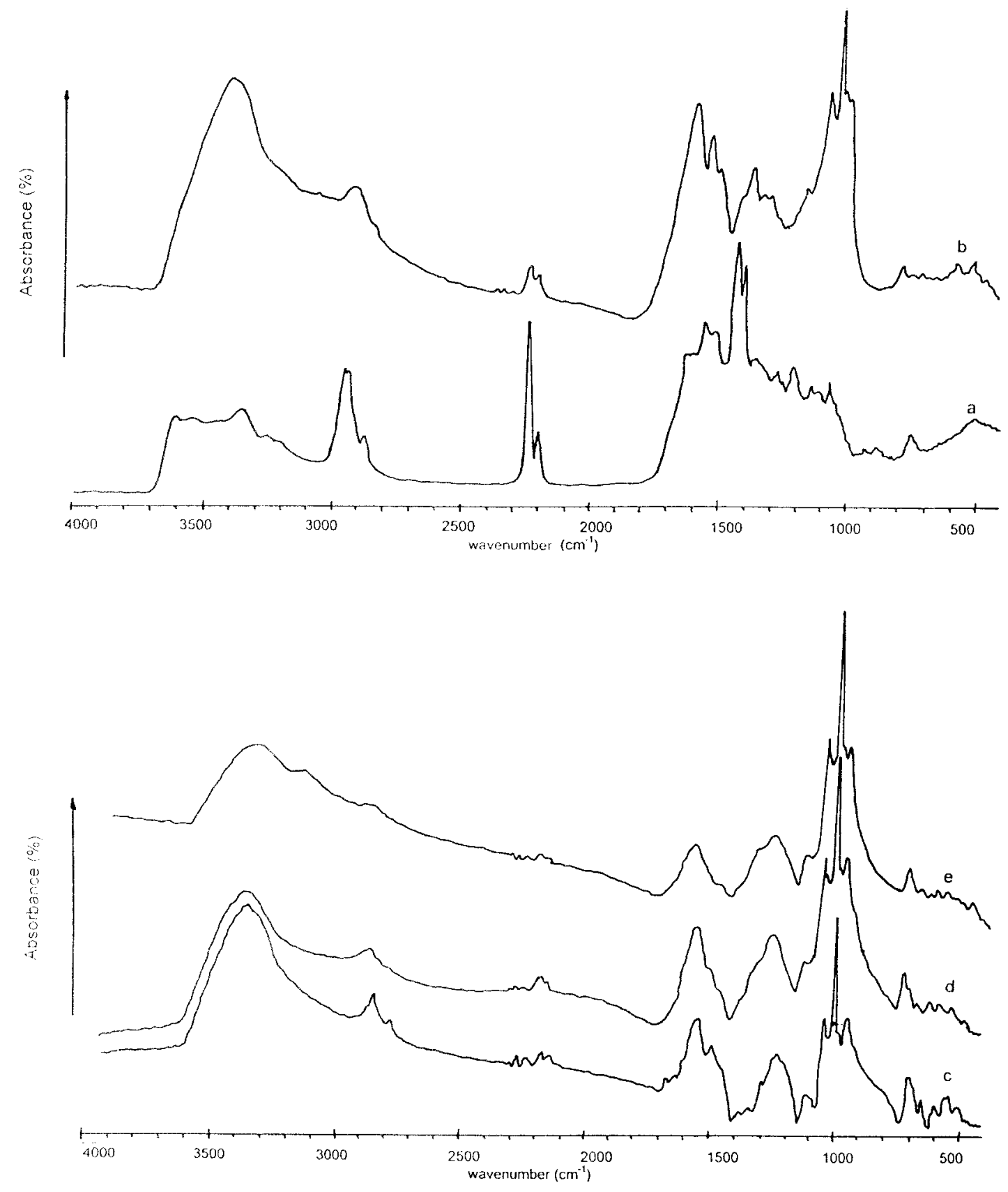

Figure 6. IR Spectra of PTh-PAN films (a) 100\% PAN, (b) $83.78 \%$ PAN-16.22\% PTh (c) 51.53\% PAN- 48.46\% PTh, (d) 41.5 $\%$ PAN-58.3\% PTh, (e) $31.7 \%$ PAN-68.3\% PTh, (f) $18.4 \%$ PAN- $81.6 \%$ PTh, (g) 100\% PTh 


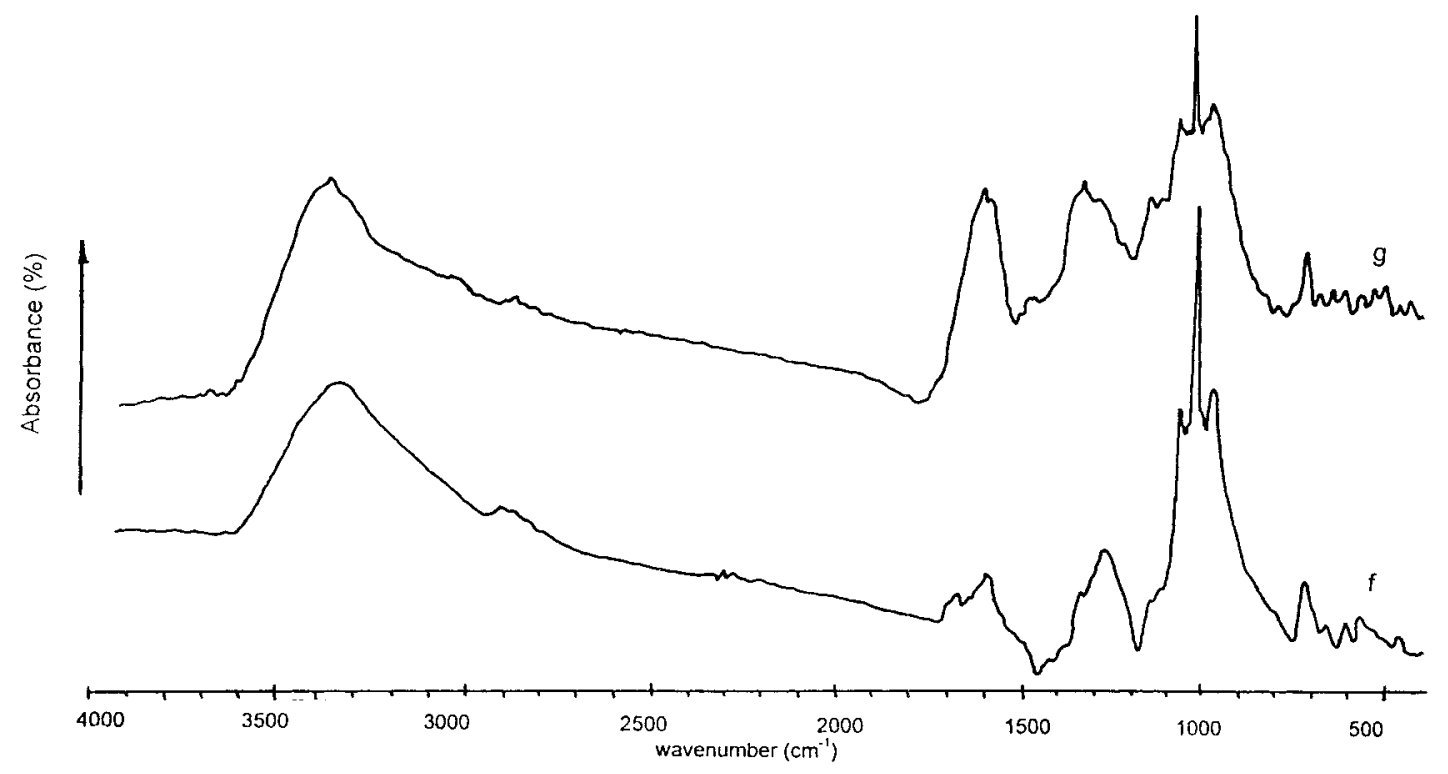

Figure 6. Continued

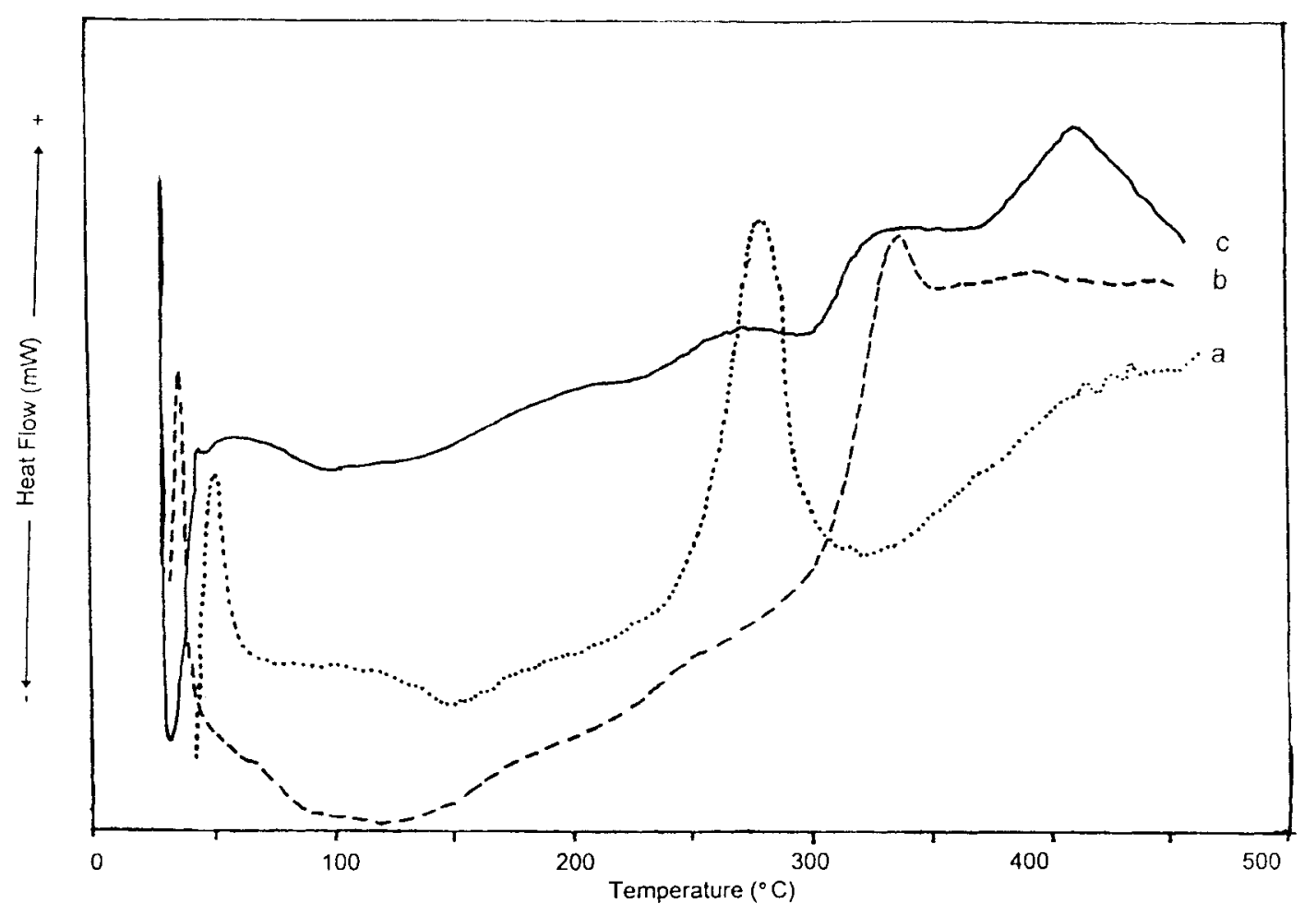

Figure 7. DSC thermogram of: (a) Cathodic polyacrylonitrile, (b) Polypyrrole, (c) Electrolytic PPy-PAN composite film. 


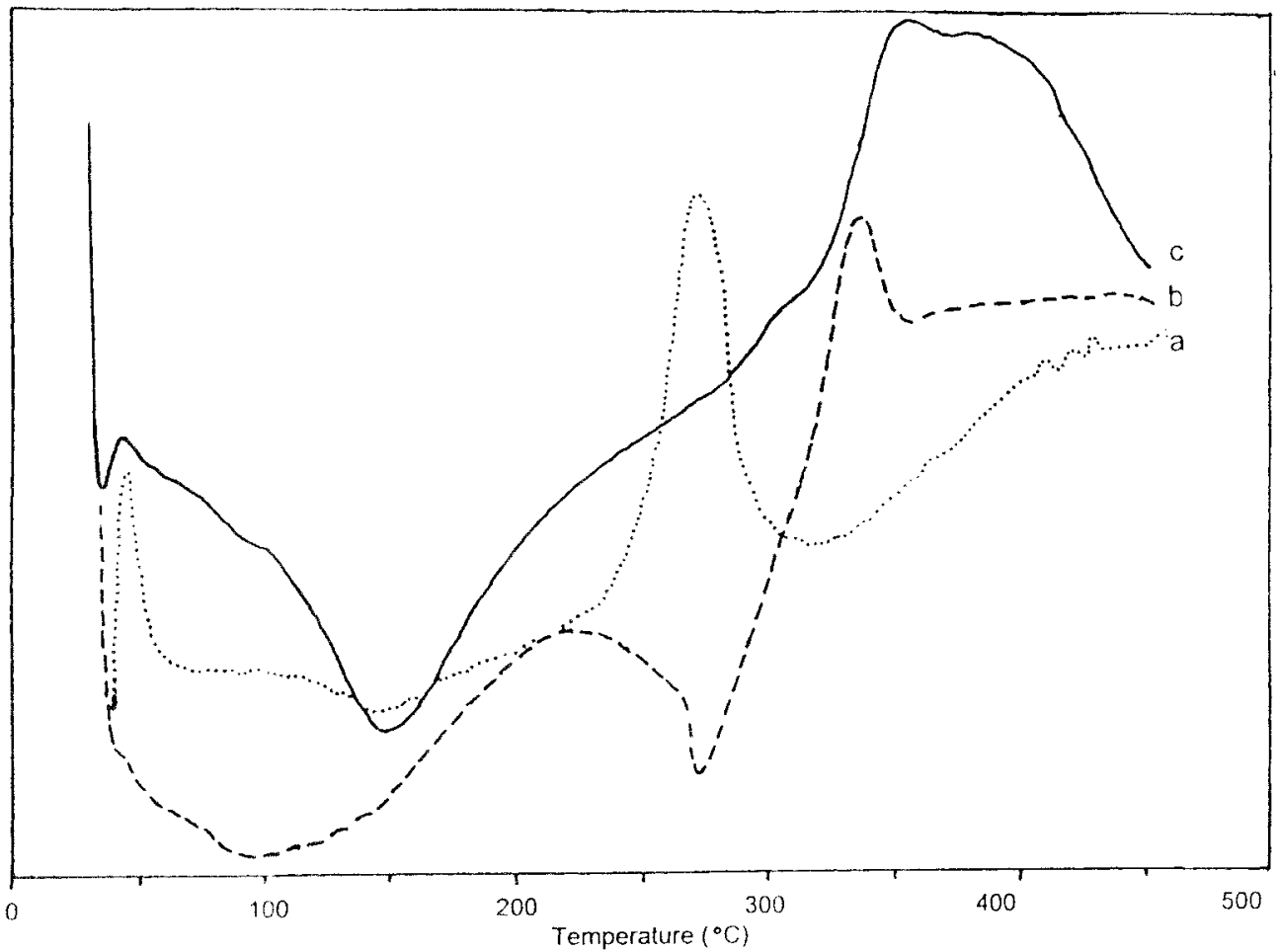

Figure 8. DSC thermograms of (a) Cathodic polyacrylonitrile (b) Polythiophene, (c) Electrolytic PTh-PAN composite film.

\section{TGA Analysis of PPy-PAN and PTh PAN Films}

TGA analysis of PPy electrolytic homopolymer film and PPy-PAN film were given in Figures 9 and 10, respectively. Those for Pth electrolytic film and PTh-PAN film were given in Figures 11 and 12, respectively. The thermogram for the cathodic PAN was already given in earlier sections (Figure 4).

All polymers have very similar types of weight loss behavior under gradual temperature increase. For instance, no matter what the polymers are (homopolymers or composite films), there exists mainly three weight loss steps. First weight loss $(20 \%)$ was observed at around $250^{\circ} \mathrm{C}$. The second gradual weight loss was observed between $225^{\circ} \mathrm{C}$ and $600^{\circ} \mathrm{C}$. The main sharp weight loss was observed between $600^{\circ} \mathrm{C}$ and $800^{\circ} \mathrm{C}$.

\section{SEM Analysis of PPy-PAN and PTh-PAN Films}

SEM anlayses reveal some morphological differences between the films. The solution side of pure PPy (Figure 13a) and PTh (Figure 14a) films show 


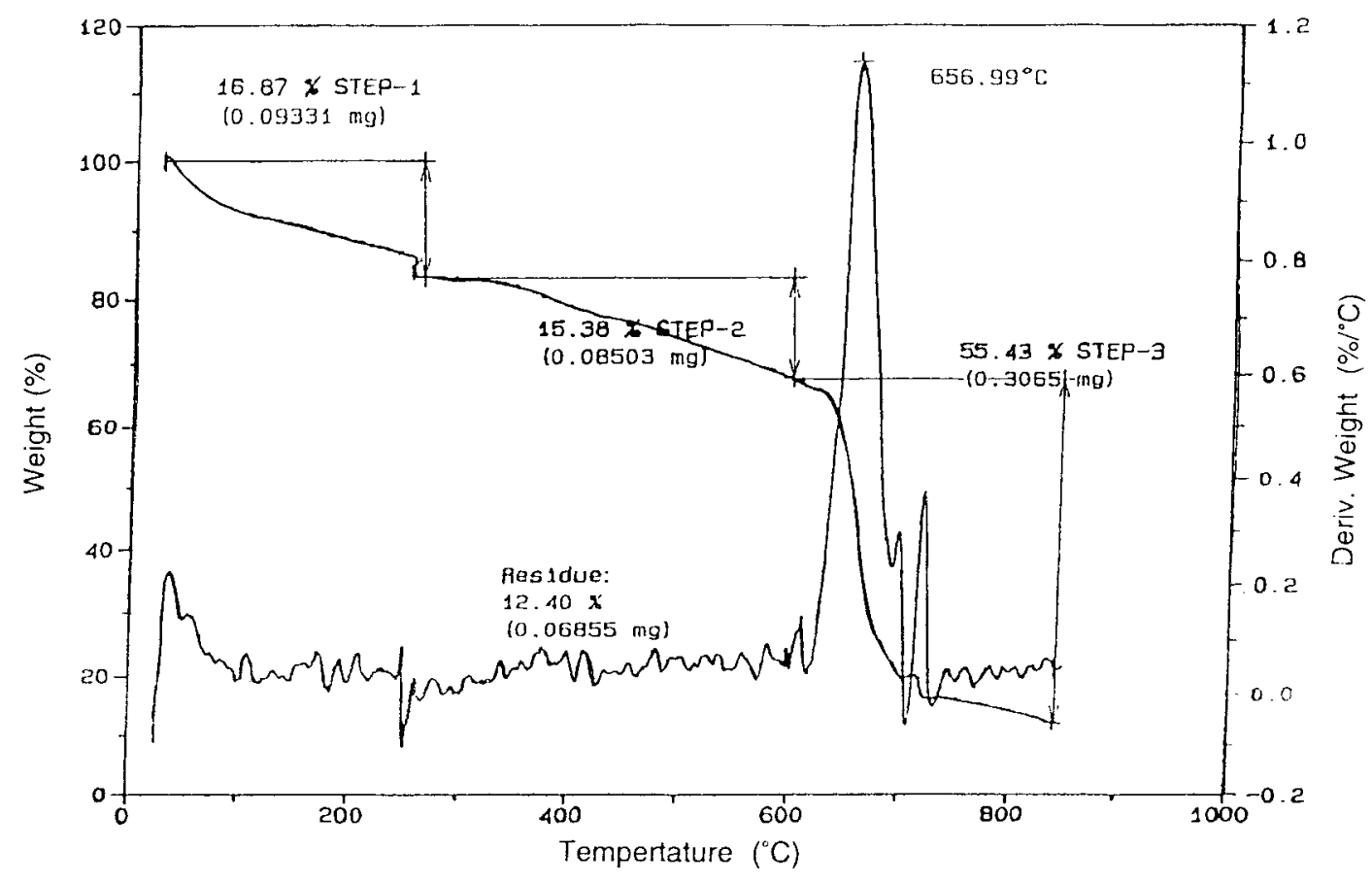

Figure 9. TGA thermogram of polypyrrole

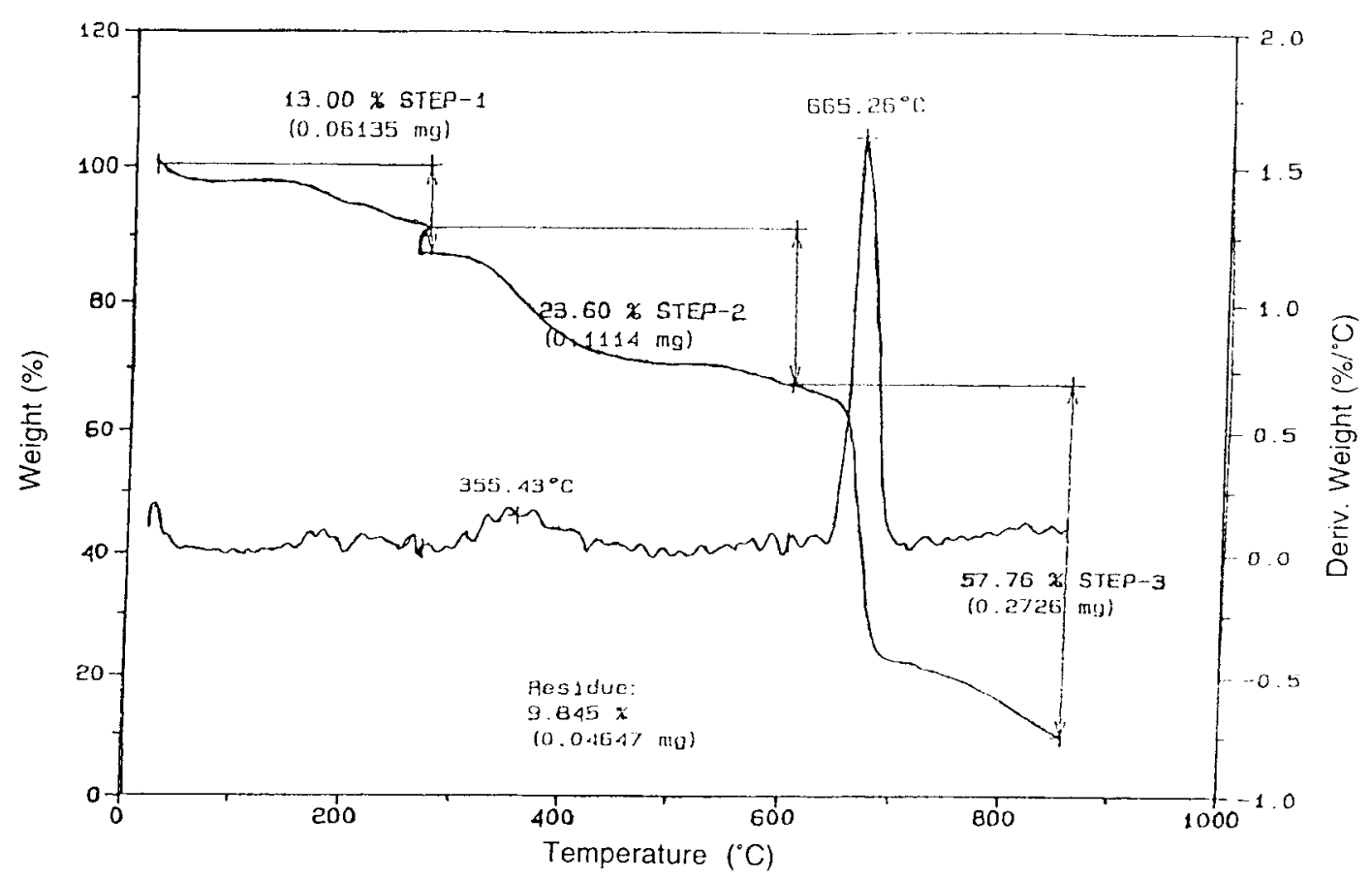

Figure 10. TGA thermogram of electrolytic PPy-PAN composite film 


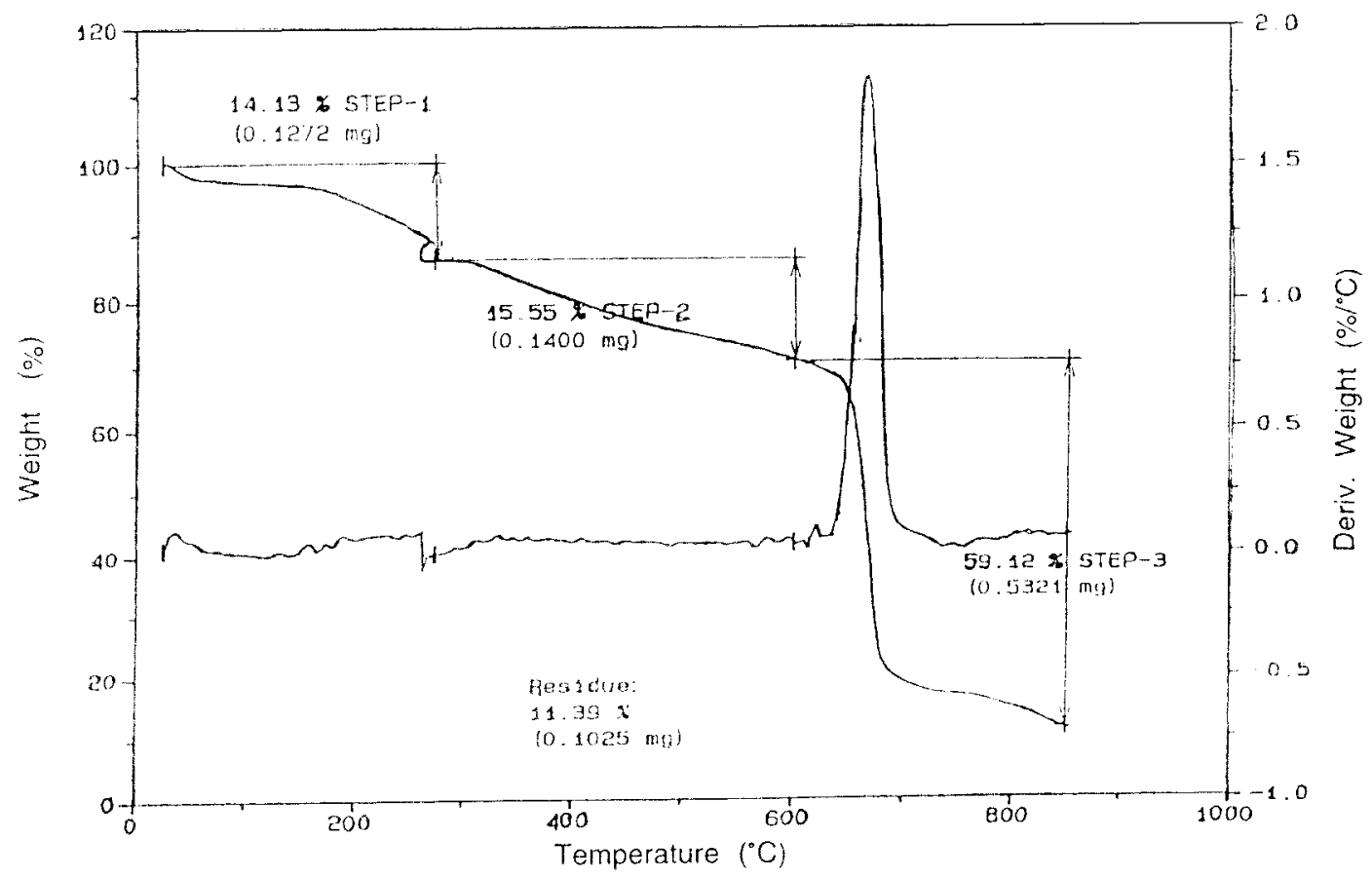

Figure 11. TGA thermogram of polythiophene

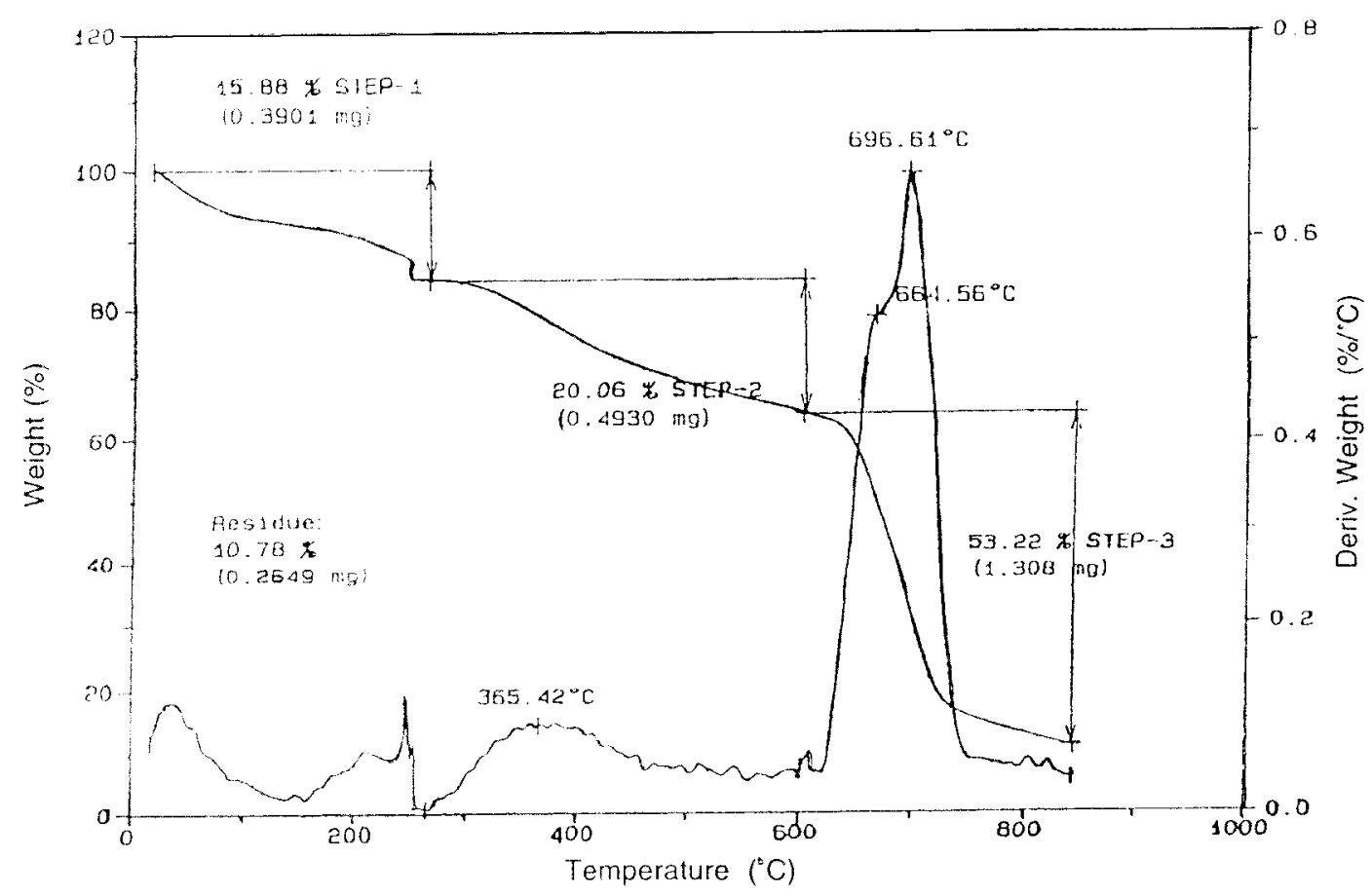

Figure 12. TGA thermogram of electrolytic PTh-PAN composite film 

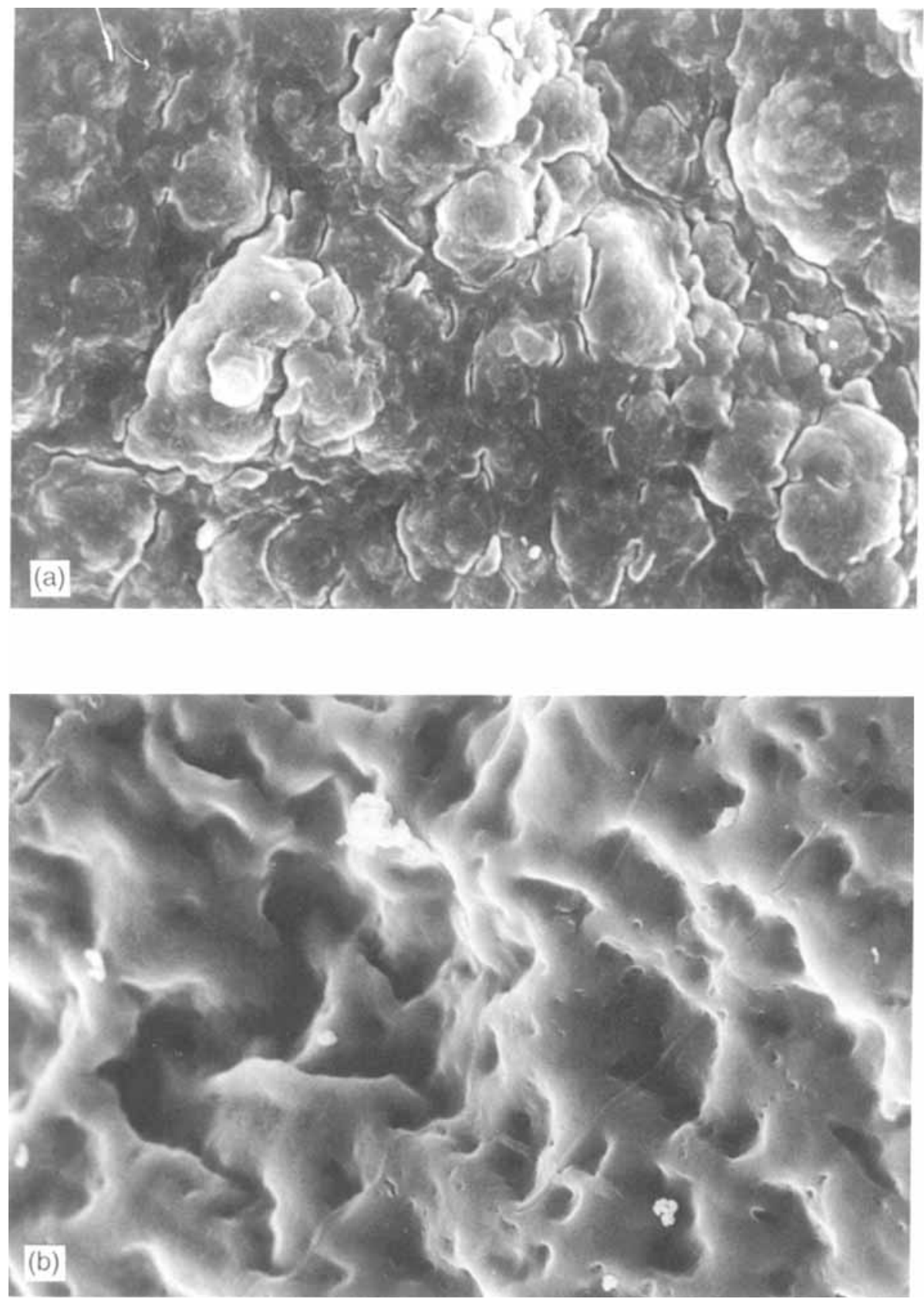

Figure 13. SEM pictures of (a) PPy solution side, (b) PPy-PAN film electrode side, (c) PPy-PAN film solution side. 


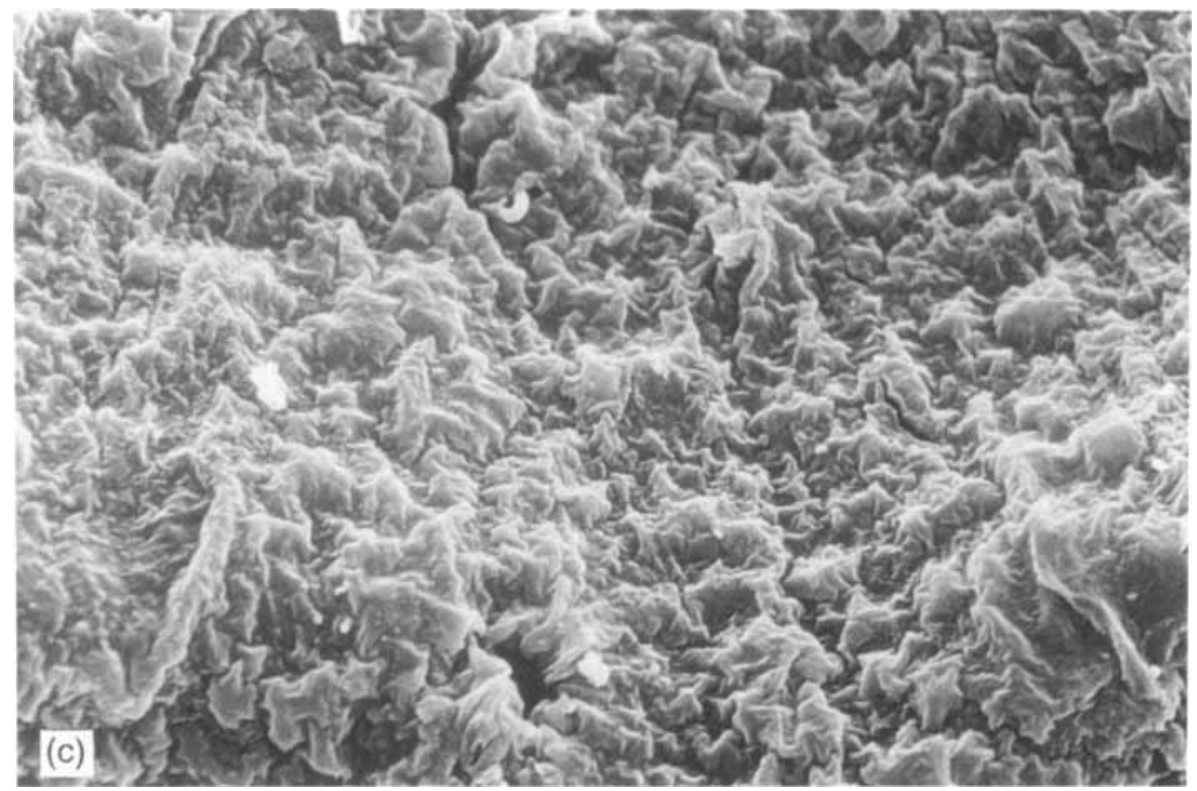

Figure 13. Continued

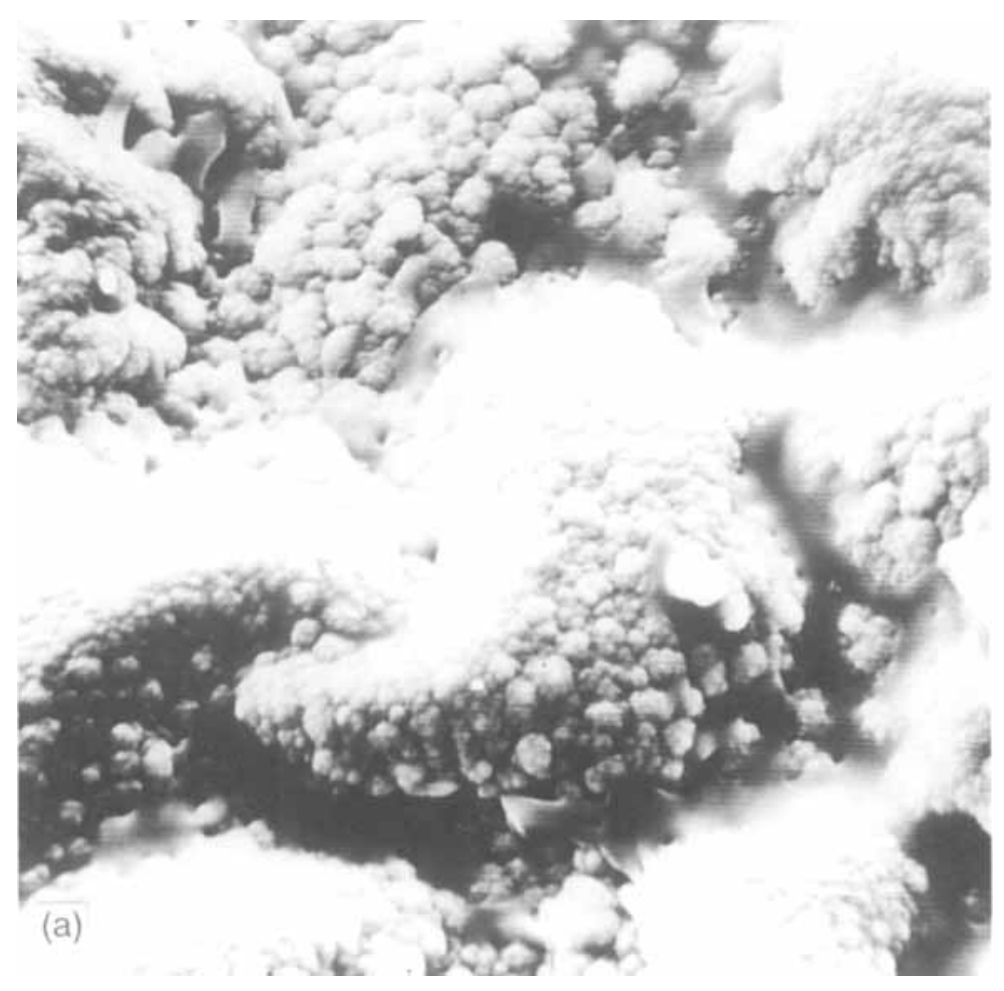

Figure 14. SEM pictures of (a) PTh solution side, (b) PTh-PAN film electrode side, (c) PTh-PAN film solution side. 

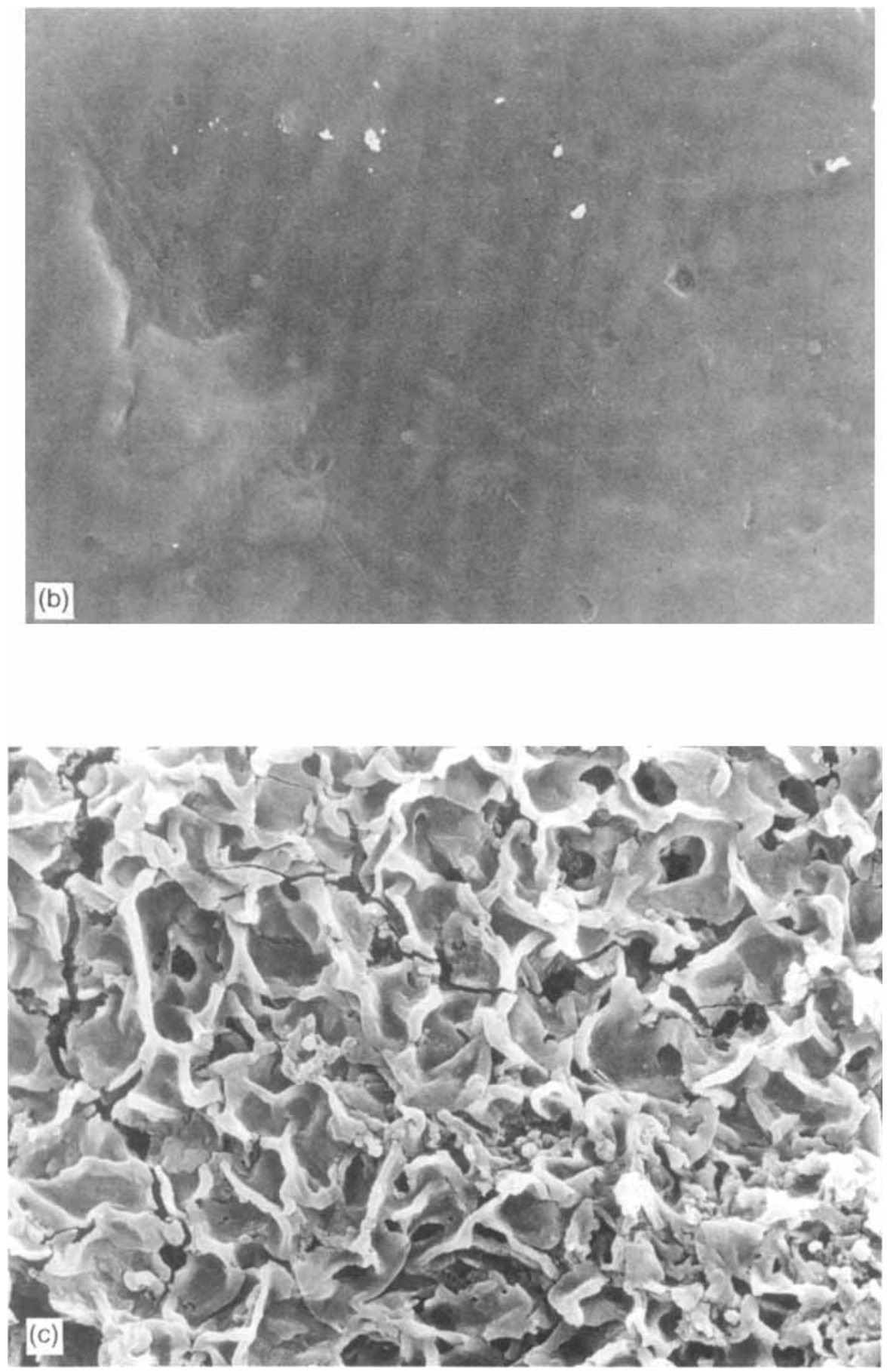

Figure 14. Continued 
hemispheres (cauliflower-like) on the surface. The SEM pictures of electrode and solution sides of the electrolytic composites PPy-PAN (Figure 13b,c) and PThPAN (Figure 14b,c) films have different appearences. In earlier reports, that difference was explained by a model [17]. Referring to this model, the diffusion of monomer molecule and the anion of electrolyte to the host insulating polymer yield different morphologies for the surfaces.

\section{ACKNOWLEDGMENTS}

We thank TUBITAK (TBAG-1422) and DPT (95K 120498) for supporting this work.

\section{REFERENCES}

[1] P. J. Goodhew, A. J. Clarke, and J. E. Bailey, Material Sci. and Eng., 17, 3, (1975).

[2] S. Damodaran, P. Desai, and A. S. Abhiraman, J. Text. Inst., 81, 4, (1990).

[3] N. Grassie and R. McGuchan, European Polym. J., 6, 1277, (1970).

[4] I. Shimada and T. Takahagi, J. Polym. Sci., Polym. Chem., 24, 1989, (1986).

[5] N. Grassie and R. Mc Guchan, Europ. Polym. J., 7, 1091, (1971).

[6] N. Grassie and J. N. Hay, J. Polym. Sci., 36, 189, (1962).

[7] N. Grassie, J. N. Hay, I. C. McNeill, J. Polym. Sci., 3I, 122, (1958).

[8] T. A. Skotheim, Handbook of Conducting Polymers, Marcel Dekker, Inc., New York and Basel, 'A. Kossmehl' Chapter 10, 351.

[9] N. V. Bhat and E. Sundaresan, J. App. Polym. Sci., 38, 1173, (1989).

[10] R. H. Norman, Conductive Rubbers and Plastics, Elsevier Publishing Company Limited, Amsterdam-London-New York (1970).

[11] H. S. Wang, L. Toppare, J. E. Fernandez, Macromolecules, 23, 1053, (1990).

[12] F. Selampynar, U. Akbulut, T. Yalçin, S. Süzer, and L. Toppare, Synth. Met., 62, 201, (1994).

[13] B. Yilmaz, U. Akbulut, L. Toppare, J. Macromol. Sci._Chem., A25 (2), 219, (1988).

[14] F. Selampinar, L. Toppare, U. Akbulut, T. Yalçin, T. Süzer, Synth. Met., $68,109,(1995)$. 
[15] F. Vatansever, A Master's Thesis in Chemistry, METU, (1995).

[16] L. Toppare, U. Akbulut, B. Yurttas, British Polym. J., 18, 4, 276 (1986).

[17] O. Niwa, T. J. Tamamura, J. Chem. Soc., Chem. Comm., 817, (1984).

Received July 15, 1997

Revision received October 10, 1997 